\title{
Mapping Syrian Refugee Border Crossings: A Feminist Approach
}

\begin{abstract}
The United Nations High Commissioner for Refugees calls the ongoing Syrian Civil War "the biggest humanitarian emergency of our era." Since 2011, over 5.4 million individuals have fled across borders throughout the region and further abroad into Europe. Western media have documented Syrian border crossings and stories through riveting journalism, interviews, photography, and maps. While the written and photographic reporting of Syrian stories use captivating imagery and testimonials to convey the traumatic experiences of individuals, these experiences are limited in the accompanying cartographic coverage. Instead, Western media's cartographic practices commonly aggregate refugees into flow lines, proportional symbols, and reference points, and frequently simplify border experiences into homogeneous, black line symbols. Flow lines, homogeneous border symbols, and other mapping conventions silence the experiences of individual Syrians and negate emotions, perils, and geopolitical issues linked to border crossings. I ask the following research questions: How can the cartographic portrayal of Syrian peoples' border experiences be improved to more fully represent their experiences? Furthermore, how can a feminist perspective inform an alternative mapping of borders and border experiences? Through a feminist lens, I have developed an alternative mapping technique that emphasizes borders as a theoretical and conceptual advancement in cartographic design and border symbolization. By rendering Syrian border stories and experiences visible with cartography, my work nudges critical and feminist cartographies forward and gives Syrians a geographic voice unavailable to them through conventional cartographies.
\end{abstract}

KEYWORDS: feminist cartographies; cartographic design; Syria; border symbolization; critical cartography; mapping stories

\section{INTRODUCTION}

Since March of 20I I, Syria has faced civil unrest, leading to what the United Nations High Commissioner for Refugees calls "the biggest humanitarian emergency of our era" (UNHCR 2014). UNHCR reports that nearly 470,000 lives have been lost, roughly 6.3 million Syrians have been internally displaced, and over 5.4 million Syrians have fled to neighboring countries-Turkey, Jordan, Lebanon, and Iraq-and beyond to the European Union (UNHCR 2017; UNHCR 2018; Human Rights Watch 2016). Thirteen and a half million people are in need of humanitarian assistance (OCHA 2018). These numbers, however, only document registered refugees. The total number of Syrians abroad is believed to be much higher.
Leaving Syria in hopes of international support and protection was, and continues to be, the only viable option for many Syrians. Even though the trek to Syria's borders is dangerous and expensive, relocating to a foreign country often outweighs the cost (UNHCR 2014). Whether crossing legally or illegally, the stories and experiences of border crossings vary from person to person (Yuval-Davis and Stoetzler 2002), while the geopolitics surrounding borders and mass refugee movements are complicated and constantly fluctuating. Borders frequently open and close due to international pressure, perceived security threats, and lack of infrastructure and resources (Diener and Hagen 2012; Jones 2012). 
Besides formalized and more traditional international borders, such as the one between Syria and Turkey, Syrians fleeing the country also cross or encounter many non-traditional borders-borders that are invisible on the landscape. The first crossing is often made at the boundaries of the home. Leaving one's home, belongings, and livelihood can be difficult, but violence and unrest drive many to cross this first border. Other such non-traditional borders include, but are not limited to, neighborhoods, rebel- and government-controlled areas, hospitals, social circles, and the body (Antonsich 2011; Näre 2014; Salamon 2006).

The written and photographic reporting of Syrian border stories by Western media uses captivating imagery and testimonials to convey the traumatic border experiences of individuals. The accompanying cartographic coverage is comparatively emotionless. Many of the maps published in Western news media utilize homogeneous border symbolization and aggregate refugees into choropleths and proportional symbol maps, losing their individual experiences (New York Times 2014; Kelly 2015b). Even maps that highlight multiple individuals and their stories often rely on identical representation strategies, neglecting the uniqueness and subjective experiences of each individual (Sullivan 2013; Kelly 2015b). The use of flow linessmooth and uninterrupted arrows connecting two known locations-is also problematic. They cross borders effortlessly, making the journey appear fluid and unburdened. These cartographic techniques erase individual experiences, dangerous perils, and legal issues linked to border crossings. While conventional techniques are familiar and useful, there remains a need for maps that more accurately portray refugee experiences, particularly experiences of borders and border crossings.

With the exception of geopolitical reference maps produced by organizations like National Geographic or Rand McNally, border lines generally lie beneath thematic data, particularly refugee displacement data (Kelly 2015b).
Borders are often placed at the bottom or near the bottom of the visual hierarchy, receding into the background as part of the base map or reference material. Often defaulting to thin, solid black lines, cartographers typically symbolize borders homogeneously (Kent and Vujakovic 2009; Kelly 2015b).

In this project, I ask the following questions: How can the cartographic portrayal of Syrian peoples' border experiences be improved to more fully represent their experiences? Furthermore, how can a feminist approach inform an alternative mapping of borders and border experiences?

These questions are purposely broad. Feminist mapping praxis recognizes the subjectivities and possibilities built into design and is less focused on identifying a narrow or universal solution. As such, I will offer one possible mapping solution to initiate conversation and bring feminist ideas and borders literature into cartographic practice and border symbolization. More specifically, I will expand the use of conventional cartographic language and visual variables to reflect individual and aggregated experiences of borders as a means to bring refugee stories back into the map. ${ }^{1}$

To illustrate feminist practice in the rethinking and designing of alternative border symbols, I will later present Amal's border story, as told in 2015. Amal is Syrian, a husband, a father, and a physician who encountered and experienced multiscalar borders-neighborhoods controlled by the Assad regime, the walls of his home, his body, and the Turkish border with Syria-in various ways. As such, a thin, black line on a map does not accurately reflect his experiences with each border. Afterward, I will present a mapping technique that aggregates the border experiences of seven interviewees. It is in this context that I negotiate the symbolization of borders and rethink "the line" as a narrative technique bound in experience.

\section{MAPPING BORDERS AND THEIR STORIES}

By ONE DEFINITION, borders signify "limits and discontinuities in space” (Popescu 2011, 161). We conventionally think of borders not only as limits and discontinuities but also as modes of organization and separation (Diener and Hagen 2012). These delineations typically appear

1. For the full project, see Kelly (2015b). permanent and static in the map. Yet with a passport, a train ticket, or maybe a smuggler, borders quickly become permeable and experienced. Borders literature has debunked the notion of spaces being strictly "trapped" by borders (Agnew 1994; Agnew 2009). Borders and territory 
are not fixed units (Elden 2013): they evolve and fluctuate, opening and closing based on security or geopolitical issues (Diener and Hagen 2012; Jones 2012). Borders are often undefined and heavily contested (Moore and Perdue 2014).

Although lines and sometimes points are convenient symbolization choices, Rumford (2006) and Newman (2006) are quick to point out that borders have their own spatiality and dimensions. Borders literature often frames them as borderlands or borderscapes - areas, not lines (Anzaldúa 1987; Rajaram and Grundy-Warr 2007; Diener and Hagen 2012). Anzaldúa (1987), for example, acknowledges the hybridity of the Chicana identity within the US and Mexico borderland region. Typically, though, cartographers do not follow suit, conventionally drawing borders as lines. Despite this uniform presentation, individuals experience borders in multiple ways (Yuval-Davis and Stoetzler 2002). Furthermore, borders literature extends the conversation to non-traditional borders, otherwise known as socio-spatial borders or contact spaces, including the home, social barriers, and the body (Antonsich 2011; Näre 2014; Salamon 2016).

While borders have a rich history in geopolitical scholarship, they also have a rich presence in past and present cartography. ${ }^{2}$ Political and administrative borders are traditionally used as units of analysis for thematic mapping or as units of organization for mental mapping and understanding the world. These borders can be quickly downloaded from sources like the United States Census Bureau and utilized for geospatial analysis and mapping.

The evolution and production of borders in cartography, and the roles of maps in international and domestic politics, have been examined by Black (1997), who pays particular attention to the mapping of borders and frontier zones beginning with Egyptian maps of gold mines and Roman cadastral maps. ${ }^{3}$ Maps and borders became increasingly important in the nineteenth and twentieth centuries with the rise of imperialism, nationalism, and war, as power became territorial and "required knowledge [or] locational specificity" (Black 1997, 135). As such, many contemporary maps remain trapped in a Westphalian model of world politics, identity, nationalism, and the us versus them mentality. Cartography adds to this territorial understanding (often inadvertently) by reinforcing borders in a visual way.

Historically, geopolitics and maps have gone hand in hand because maps are the "perfect symbol of the state" as they continually reinforce each other through sovereignty and the "boundedness" of the borders that maps depict (Moore and Perdue 2014, 893). The use and influence of geopolitical maps have been well documented and critiqued by contemporary theorists. Furthermore, geopolitical maps have been problematized and deconstructed as sources of power, hegemony, visibility, and masculinity (Harley 1989; Wood and Fels 1992; Black 1997; Kwan 2002a).

Given the stigma surrounding their use and implications, political geographers have limited their utilization of traditional geopolitical maps and "geopolitical cartography has never been recovered" (Moore and Perdue 2014, 894). Moore and Perdue challenge researchers to find alternative ways of mapping that more accurately reflect contemporary geopolitics. From a critical geopolitical standpoint, they visualize the contested territory and lived realities of individuals in the Kashmir region, challenging the conventional, state-centric ideal often depicted in maps (898).

The use of visual variables to symbolize borders has also been examined in relation to visualizing uncertainty by MacEachren (1992, 13-14), who proposes color saturation and focus or crispness as optimal visual variables for representing uncertain spatial information. Both of these can be easily and effectively applied to border symbols. In practice, however, international borders in EU topographic maps and maps published by Western news media outlets are most often depicted as solid black lines accompanied by categorical tint bands or color highlighting (Kent and Vujakovic 2009; Kelly 2015b).

Cartography's role in solidifying our understanding of borders has also been explored by artists, who can contest conventional border representations and reveal hegemonic discourses, border complexities and experiences, and embodied borders. Guidice and Giubilaro (2015) examine the imagination and production of borders through art, contending that conventional borders are limited in their

2. In this paper I draw predominantly on literature discussing international, social, and embodied borders and borderlands. For discussion of "natural" or environmental borders such as ecotones and their cartographic depiction, please see: Küchler (1988), Rossum and Lavin (2000), and McColm (2012).

3. Black (1997) also recognizes the influences of Chinese and non-Western cartographies in productions of power, politics, and borders in Western cartography. See Black (1997, 26-28) for more details. 
symbolization and dimensionality because they are commonly simplified into lines on a map. This simplification is a "clear power strategy developed by the nation-state to define and manage its space" (Guidice and Giubilaro 2015, 81). Continuous lines are convenient symbols for borders because of their perceived permanence and uncontested fixity; they appear static, essential, and unexperienced.

Dashed lines are also used to symbolize borders, albeit with a different message. Gaps and dashes disrupt continuous lines and present a sense of fluidity, contestation, and impermanence. Guidice and Giubilaro (2015) present artists who transform understandings of borders and representation through imagination, dis-bordering, and worn realities. However, they focus solely on the transformation and the symbolization of borders in media such as artwork, literary landscapes, iconography, and film, thus neglecting cartography.

André Reyes Novaes (2015) explores the intersection of map art and critical geopolitics at Colombia and Venezuela's shared border. Both Novaes (2015) and Black (1997) point out that maps have shaped representations and conceptualizations of the state and have instilled imagined divisions between countries. The static visual representation of borders in maps contradicts critical, geopolitical understandings of dynamic and experienced borders.

Novaes (2015) studies this visual representation challenge in Projecto Mapa. Artists from the region were presented with a map that merged Colombia and Venezuela into one imagined country-and were asked to create new maps showing the open, transnational relationship between the two countries. Projecto Mapa failed in its goal of creating a borderless map. In the absence of provided borders, artists routinely replicated conventional border delineationsalthough with new symbolization techniques (stitched lines and doves representing peace). The redrawing of the border between Colombia and Venezuela reflects strong national identities and imaginations. Novaes concludes that, "borders remain important [and mapped] in our borderless world" (Novaes 2015, 138).

The cartographic representation of border experiences can also be informed by literature on maps and storytelling. While maps ground stories in space and help "decipher" landscapes, they have also been explored not only as supplements to the story, but as primary, powerful, and "compelling forms of storytelling” (Caquard 2011, 136; Reutzel 1985; Wood 1987). The "story map," defined by Robert Macfarlane $(2007,145)$ as "deep maps ... that acknowledge the way memory and landscape layer and interweave" emerged from these conversations of power, storytelling, and narrative (Caquard 2011). Narrative mapping combines story and discourse that "transcends mere description [story] ... by shaping it with meaning" (Pearce 2008, 21; Chatman 1978). Contemporary mapmakers have re-explored cartographic language and narrative to map stories that reflect and emphasize experience, albeit in different ways (Lynch 1960; Pearce 2008; Kwan 2008; Nold 2009; Pearce and Hermann 2010; Knowles, Cole, and Giordano 2014).

With the development of Web 2.0 and interactive mapping, story maps have also been utilized online by news media sources, data journalists, and novice mapmakers (Crampton 2009; Esri 2012). The New York Times (Ashkenas et al. 2014), The Washington Post (Sullivan 2013; Karklis et al. 2018), and National Geographic (Salopek 2015) are three notable online sources that are on the cutting edge of story mapping and data visualization. These media outlets, among many others, approach visual storytelling in innovative ways as technology continues to evolve. Borders, border stories, and their depiction in maps, media, and visual stories are bighly relevant today. As such, understanding and rethinking border symbolization in print and online mapping is paramount.

\section{CRITICAL AND FEMINIST PERSPECTIVES ON MAPPING}

THE RISE OF CRITICAL AND FEMINIST perspectives in the social sciences in the last three decades has directly challenged conventional cartographic methods (Harley 1989; Crampton 2011). Feminist perspectives are diverse. Yet, there is common agreement that complete objectivity or truth cannot be fully achieved, and all knowledge is situated in personal subjectivities and social contexts (Haraway 1988; Harding 1986; Kwan 2002a; D'Ignazio and Klein 2016). Although several scholars and mapmakers have methodologically explored feminist 
standpoints in cartography, the representation of difference and subjective experiences has often been limited (Kwan 2002b; McLafferty 2002; D’Ignazio and Klein 2016). Using feminist theory as a framework, I draw on four particularly relevant themes: the body, intersectionality, reflexivity, and transformation.

Research and theory on the body is complex and as a result, there is no widely accepted definition of the body (Longhurst 1997; Valentine 1999). In feminist research, however, the body can be recognized as a geographic location, the "closest in" and most intimate geography (Rich 2003, 212). Transfeminist poet, Joy Ladin (2014), recognizes the body and identity as "expressions of a single self," limited by language, and in the case of mapping, representation. Furthermore, the body can be viewed as "tactile space" that is bound and bordered, separating the internal from engagements with the external world (Valentine 1999, 331; Salamon 2006). This is especially relevant to mapping, as cartographers typically depict the body as a point or line, rather than an area (Kelly 2015b). Additionally, individual bodies are frequently left unspecified, undifferentiated, and "colourless" in many cartographic depictions, leaving them appearing homogeneous (Rose 1993, 31). These techniques silence the experiences of and interactions with the body. Similar to D'Ignazio and Klein (2016), feminist perspectives in mapping recognize differentiated bodies and affective experiences as instrumental to visualization.

Like feminist understandings of situated knowledge, bodies are also situated because they are unique and complex. Cartographers and data visualization experts often rely on categorical data, aggregating bodies and individuals into groups or binaries based on gender, ethnicity, nationality, or religion, to simplify a map's message (D'Ignazio and Klein 2016). In reality, an individual may identify with multiple, entangled categories. A feminist approach recognizes that the body and the individual are nuanced and deeply complex, with many, often intersecting identities (Crenshaw 1991; Mohanty 2003). Intersectionality refers to power differentials that are multidimensional and shaped by intersecting notions of "race, class, gender, sexuality, ethnicity, nation, ability, and age" (Crenshaw 1991; Collins 2015, 2). By recognizing intersectionality, cartographers can avoid binaries, overgeneralizations, and the categorization of individuals by focusing on the complexities, pluralisms, and subjectivities of individual identities, experiences, and knowledges (D'Ignazio and Klein 2016).
Cartographically, categories are frequently used to reduce complexity and communicate a message or story in a map more readily. When asked to create bodily categories, Mohanty suggests looking for "common difference" between individuals, a strategy that simultaneously recognizes alliance and division across groups, allowing aggregation or grouping through reflexive practice (Mohanty 2003, 503). Mohanty, for example, uses this framework to recognize the differential impacts of race, class, and gender on women in "Third World" contexts, yet simultaneously recognizes their commonality, as systems of power maintain dominance across contexts (2003). Further, common difference acknowledges that "the differences and borders of each of our identities connect us to each other" and requires "informed, self-reflexive" solidarity and practice (Mohanty 2003, 530).

How have cartographers incorporated intersectionality into practice? Pearce and Hermann (2010)'s They Would Not Take Me There features multiple voices overlaid on a map of Samuel de Champlain's travels in North America, including those of Champlain and the indigenous peoples he encountered. Several sequential insets recount narratives and lived realities simultaneously. Although difficult to digest in one take given its complexity, they place several intersectional experiences in the map.

Another possible cartographic example of intersectionality and common difference is the work of Kevin Lynch (1960) in Image of the City. Lynch, an urban planner, used cognitive mapping to understand how individuals experience the city. In his approach, Lynch worked across scalesthe individual and the aggregate-beginning with maps sketched by participants of their urban experiences. He then quantified and aggregated his participants' experiences into a single map. Lynch used ordinal symbolization to reflect the degree to which city elements were experienced by the aggregate. Lynch was able to create common difference in his aggregated maps because he understood each subjective experience of the city first.

Feminist literature also addresses the responsibility of scholars and cartographers to recognize any potential influence, bias, or subjectivities in a given project (England 1994; Mohanty 1988; Mohanty 2003). Also known as reflexivity, this is an inward-facing reflection on one's own positionality and recognizes that all knowledge stems from somewhere (Kwan 2002a; Haraway 1988). As such, a reflexive approach to mapping contextually situates or 
grounds the project and emphasizes the integrity of the knowledge producer or mapmaker.

Researchers and scholars often incorporate a reflexivity or positionality statement at the beginning of their work. Cartographers, however, are less likely to document their subjectivities and bias in the map. Pearce (2008) is explicitly reflexive in writing about her map, Framing the Days, but is also indirectly reflexive in the map itself, by separating her own voice from the voice of her map's subject-a fur trader traveling through the Great Lakes. Pearce marks this distinction by using two contrasting typefaces: a sans serif typeface for the fur trader's voice and a serif typeface for her own voice. This technique quickly and effectively informs the reader who is speaking and recognizes Pearce's position as cartographer outside the story.

Inclusion and transformation are additional theoretical concepts within feminist theory. Inclusive feminism emphasizes the incorporation of marginalized groups into roles predominantly held by white, heterosexual men. In contrast, a transformative approach dismantles social constructions such as gender (D'Ignazio and Klein 2016). Similarly, a transformative approach to cartography first deconstructs the map and then restructures how it is conceptualized. Cartographic transformation rethinks, redefines, and re-visualizes the map, its marks and symbols (Cresswell 2013).

Borders, border stories, and cartographic symbolization provide a unique framework to map Syrian refugee border crossing experiences. While each subarea has a rich and evolving cartographic history, their intersection has not been previously explored. Additionally, a feminist perspective adds an additional layer of individualized experience and complexity to the map page. By focusing on the intersectionality of refugees and their stories as well as the reflexivity of the cartographer, individual experiences can be prioritized and separated from the voice of the mapmaker. With this lens, I navigate the experiences of traditional and non-traditional borders, including the body, and cartographically rethink and transform border symbolization as a new narrative mapping technique.

\section{METHODS FOR PERSONAL MAPS}

\section{AMAL'S STORY}

IN THE SPRING OF 2015, I conducted a series of semi-structured interviews with Syrians and humanitarian workers in the region (Kelly 2015b). Our conversations centered on the Syrian crisis, personal stories, and border insight or experiences. Here, I present Amal's story, a personal account of life in Syria during the conflict. His story includes encounters with various types of borders inside and outside of Syria. Additional stories are available online (Kelly 2015a) and in print (Kelly 2015b).

Amal is a physician, a husband, a father, and a Syrian. He taught at a medical school before the revolution began. Amal played an important role as a physician during the first years of the civil war, often working for one or both sides of the multifaceted conflict. He fled Syria in 2013 and now resides in Turkey without his wife and daughter. Amal's story centers on various borders, as well as safety, family, mobility and his experiences as a physician during the crisis.

Amal was not politically active in the conflict at the beginning of the revolution because of previous brutal

experiences with the Assad regime. A significant event called him to the field:

After the famous "Central Square" massacre in my own city Homs, I found myself obligated to help the civilians and work secretly in local field hospitals. People did not trust going to the governmental hospitals, fearing of arrest, torture, and even execution. I continued to work secretly, while the situation continued to get worse. The peaceful revolution slowly started to turn into what looks like a civil war....

The revolution erupted throughout his city with continued shooting and bombings. Fear was evident in his household too. He said:

My wife ... had to quit her laboratory specialty training, and my daughter, who was only two and half years old, could not stop crying every time she heard a shooting or a bomb near our home. For those reasons and others, I had to 
make my wife and daughter flee the country toward UAE [United Arab Emirates] in May 2013.

Amal's wife and daughter crossed Syria's border alone as Amal stayed behind to continue providing medical aid.

Eventually, the Syrian government regime took over his city, which he called the "most active war zone." A total siege limited Amal's mobility and he was "unable to move in and out easily." Areas controlled by the regime were informally bordered, preventing his movement. Although informal and non-traditional compared to administrative boundaries, regime-controlled areas presented very rigid and real boundary lines with consequences.

With restricted mobility, Amal continued to work as a physician in the field, feeling obligated to aid both sides of the revolution. His dual responsibility, however, was difficult in practice:

While medically helping both sides of the war felt the right thing to do, this very issue placed additional pressure on me. Not only I had to avoid disclosing my [role] in helping the rebels from the government, but also I had to face increasing scrutiny from the rebels because of my help to the other side, namely the Shabiba [government thugs].

Working in this borderland, aiding both sides, was also extremely dangerous, and eventually forced Amal to flee. He said:

I received multiple threat letters, not only concerning myself, but also concerning my parents and my siblings. In fact, I was physically hurt in one incident. Eventually, the pressure pile so high on me, I had no other way to survive exception running away, and so I did. I secretly managed to travel to Turkey.

In Turkey, Amal began working with an international NGO and continued his work as a physician helping Syrians abroad. Although Amal left Syria, a part of him remains transnational. He ended his story with this sentiment:

Although I have physically moved out of the country ... my heart and soul remain attached there, where I have the rest of my family suffering the daily bombardment and shooting from the Syrian government.

\section{AMAL'S MAPS}

After completing, transcribing, and analyzing my seven interviews, including Amal's, I began the process of mapping. Before making a single mark on the page, I became completely immersed in the stories by not only reading the interview transcripts, but also listening to the recordings.

Borders and border crossings began to emerge. I coded themes and identified border experiences that were specific to each individual and those that overlapped between stories. Before turning to mapping software, I identified the progression of events as told by each participant (narrative ordering) to organize their stories and encounters with borders (Figure 1).

Next, I turned to mapping software (Esri's ArcMap). I began with one story and mapped the sequence of events using international boundaries and place names for geographic context and chose flow lines to depict movement, following traditional cartographic conventions (Figure 1). I quickly became dissatisfied with my symbolization choices, as the symbols I was choosing did not match the stories I was hearing in the recordings. My conventional techniques removed key events and silenced the emotions and experiences within the story. Many borders and experiences like those of Amal's district and his body, for example, were rendered invisible because there wasn't a shapefile available or geographic information attached.

After listening to the first story multiple times, I iteratively re-symbolized the marks on the map, with each attempt trying to create a more truthful depiction or symbol of his story.

Through each iteration, I learned more about each border experience and what was needed in the symbol and the layout. Continuing to the other interviews, I gradually refined my symbolization techniques in each map until I found a useful design and layout (Figure 2). The map elements in the layout are discussed in detail below, beginning with the central map (Figure 2, map element 1 ).

Borders are often encountered in different ways by different people. In conventional cartography, these disparate 


\section{Progression of Events and Border Stories}

1. When the Syrian revolution erupted in March 2011 , I was holding a teaching position in Aleppo School of Medicine, and preparing for a $\mathrm{PhD}$ advance degree in histopathology. My previous experience with the Syrian regime's brutality prevented me initially from direct involvement in the revolution.

2. After the famous "Central Square" massacre, in my own city Homs, I found myself obligated to help the civilians and work secretly in local field hospitals. People did not trust going to the governmental hospitals, fearing of arrest, torture, and even execution.

3. I continued to work secretly, while the situation continued to get worse... Eventually, the government managed to have a total siege over the Old City, which was the most active war zone then. I was no longer able to help over there.

4. My wife had quit her laboratory specialty training, and my daughter, who was only two and half years old, could not stop crying every time she heard a shooting or a bomb near our home... For those reasons and others, I had to make my wife and daughter flee the country toward UAE in May 2013.

5. My own district was under a sub-total siege and I was unable to move in and out easily.

6. I had to treat both sides of the war, the rebels and the Shabiha. My medical ethics and humanitarian side forced me to do so... While medically helping both sides of the war felt the right thing to do, this very issue placed additional pressure on me. Not only I had to avoid disclosing my role in helping the rebels from the government, but also I had to face increasing scrutiny from the rebels because of my help to the other side...

7.I received multiple threat letters, not only concerning myself, but also concerning my parents and my siblings. In fact, I was physically hurt in one incident.

8. Eventually, the pressure piled so high on me, I had no other way to survive except running away, and so I did. I secretly managed to travel to Turkey... where I continued to work in humanitarian aid to my own people.

9. Although I physically moved out of the country, but my heart and soul remain attached there, where I have the rest of my family suffering the daily bombardment and shooting from the Syrian government.

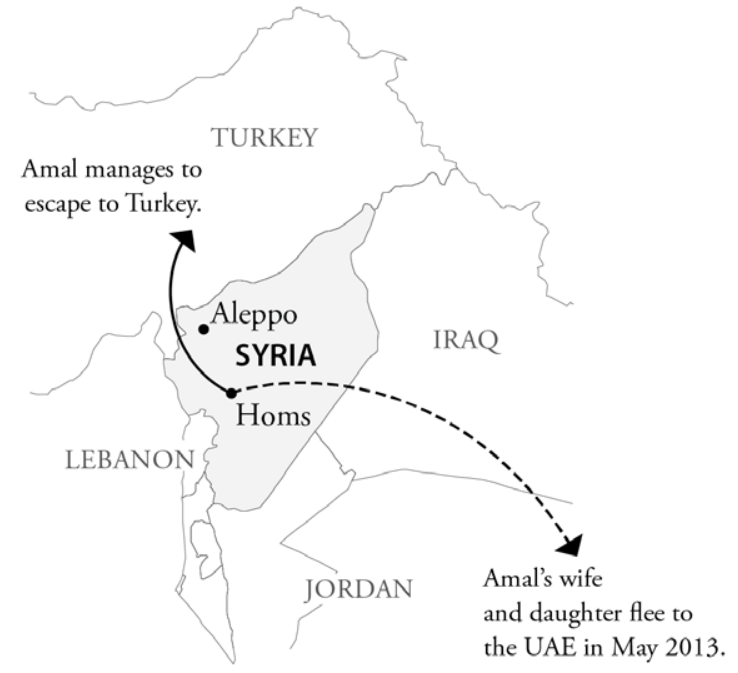

the UAE in May 2013.

Figure 1. Progression of events and border experiences from Amal's story. Borders are highlighted in bold in the left panel. The map on the right uses conventional mapping techniques, based on Sullivan (2013), to map out Amal's story.

experiences would typically be collapsed into one line. I avoided aggregation by instead placing each border experience onto its own map page, making all borders and border experiences equally visible. Instead of focusing solely on traditional country boundaries (a very state-centric convention), any type of border experience is shown on the central map for its individual page. These individual pages show border experiences as told by each interviewee, and reveal non-traditional borders such as the home, the neighborhood, or the body, which may otherwise go unseen. The centrality of the featured border and the white space surrounding it focuses the reader's attention and brings each border experience to the forefront. Few features are symbolized other than the border, to highlight and communicate the intimacy and primacy of the experience- - technique adapted from Pearce (2008).

The borders displayed in the central map on each map page are symbolized in specific ways. Borders with definite geographic information attached, such as the Syrian border, the city limits of Damascus, or boundaries of a Zaatari refugee camp, are projected and displayed as spatially "accurate." Other, more abstract spaces with undefined locations such as an unnamed hospital, or the body, are displayed as hollow squares. Like geographically defined polygons such as the Syrian border, each square space is bounded with an abstract border. In other words, if a border did not have a corresponding shapefile (a digital file of 


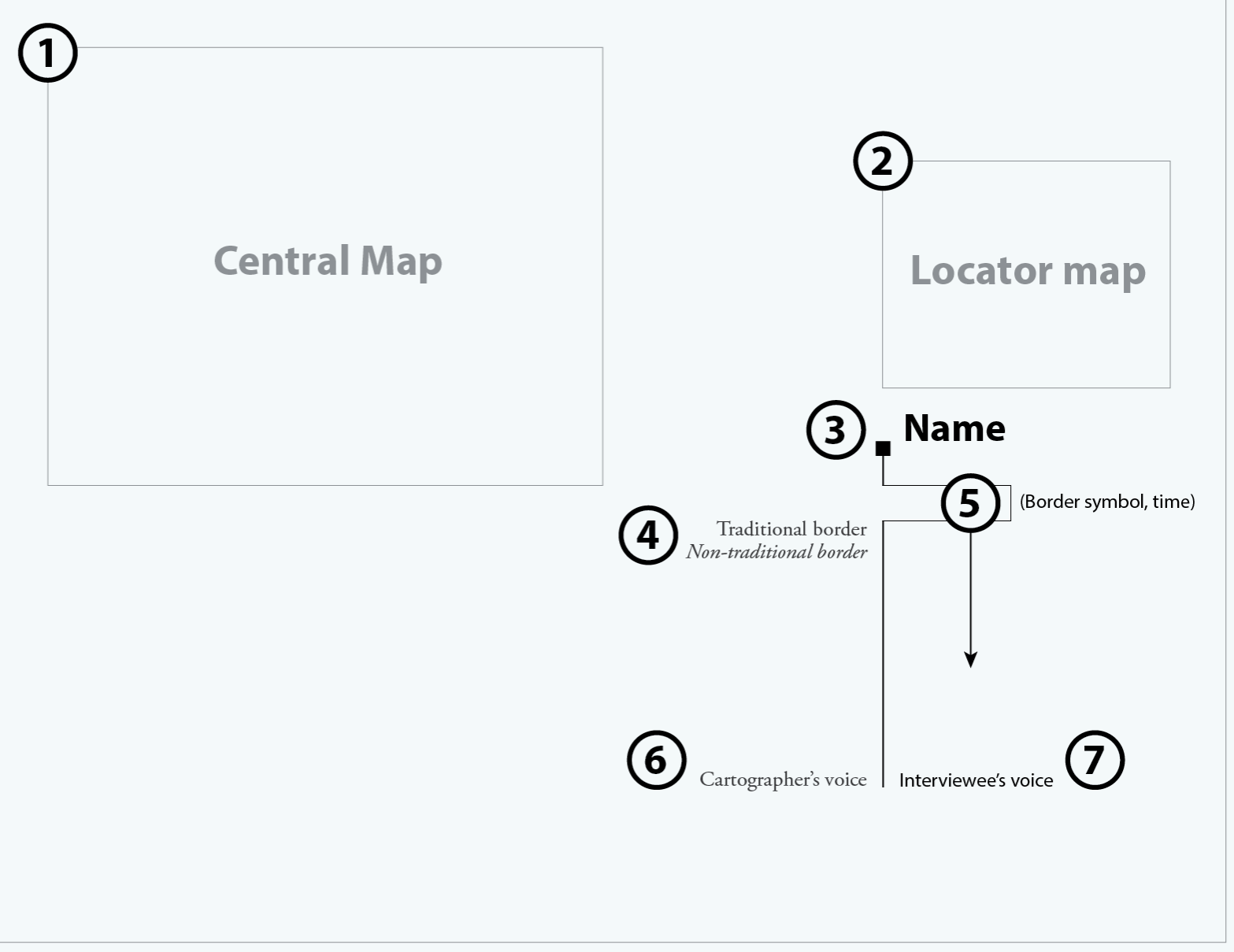

Figure 2. Map layout schematic. Each map element is numbered and described in the text.

coordinates for a specified feature), I defined the space and border abstractly. The abstract square shape was necessary because of its flexibility; it could be easily applied to variety of non-traditional borders. This technique enabled me to bring both non-traditional space and non-traditional borders, such as the body, into the maps.

Each border in the central map is symbolized according to the intensity of individual experiences and the border's porosity, using a bivariate scheme that relies on the visual variables of size and arrangement (Figure 3). I used the size (i.e., thickness) of the lines to demonstrate the intensity of an experience. For example, a line increases in size if the emotional toll of the experience increases. A line becomes thinner if the experience is understated or minimal. Using the interview recordings, the transcripts, and my notes as a guide, I gauged each interviewee's expression of a border and documented specific words, phrases, or the tone that defined each experience. I placed each word, phrase, or tone along the $\mathrm{x}$-axis of the bivariate line scheme to reflect the intensity of the experience it described.

I then used the visual variable of arrangement (the combination of gaps, dashes, and solid lines) to symbolize the porosity of each border. Empty spaces between dashes suggest permeability and movement; the larger the space between each dash, the more porous the border. In contrast, solid lines suggest a barrier with limited mobility. 
I recorded the words, phrases, or tone from each interview that described each border's porosity and placed each description along the y-axis of the bivariate line scheme (Figure 3). For example, the words "fluid" and "porous" were used in one story to describe the Syrian-Turkish border. I symbolized this border as a dashed line to reflect its fluidity. In contrast, the words "controlled," "barrier," or "strict" suggest limited movement and boundedness. Solid, impermeable line symbolization was used to illustrate such descriptions. The bivariate line symbolization scheme allowed me to simultaneously display both intensity of experience and porosity. Figure 4 displays the same symbolization scheme as applied to the Syrian border. From there, I assigned a symbol to each border experienced or described by the storyteller using this grammar.

Borders are typically labeled to provide spatial context for the reader. In the central maps (Figure 2, map element 1), each border is unconventionally labeled to correspond with the individual's subjective experience of the border. Similar to van Swaaij and Klare (2000), Huffman (2010), Pearce and Hermann (2010), and McClean (2017), the label-a simple word or phrase from the interview or story-connects the reader to the experience and in this case, the individual. The label dismantles the aggregation of experiences in conventional symbolization by removing uniform labels and replacing them with labels that render the individual visible, using their voice to acknowledge the border experience. This experiential labeling technique reinforces the meanings of the new line symbols previously discussed. Simply stated and in sum, the border is defined by the experience.

Each page has its own locator map in the right panel (Figure 2, map element 2), which serves two purposes: to orient the reader by identifying the border's approximate geographic location (if known), and to allow comparison. The locator maps highlight elements within each story by bringing place names or movement to the forefront in black. Supplementary information is then recessed using subdued grays. The locator maps are drawn with conventional cartographic techniques such as uniform lines for country boundaries, points for refugee camps, and flow lines to demonstrate movement and directionality. Although minimized and secondary in importance to the central map, the locator maps together with the central map provide a contrast between conventional representation of borders and what can be done to symbolize borders to more accurately represent experiences.

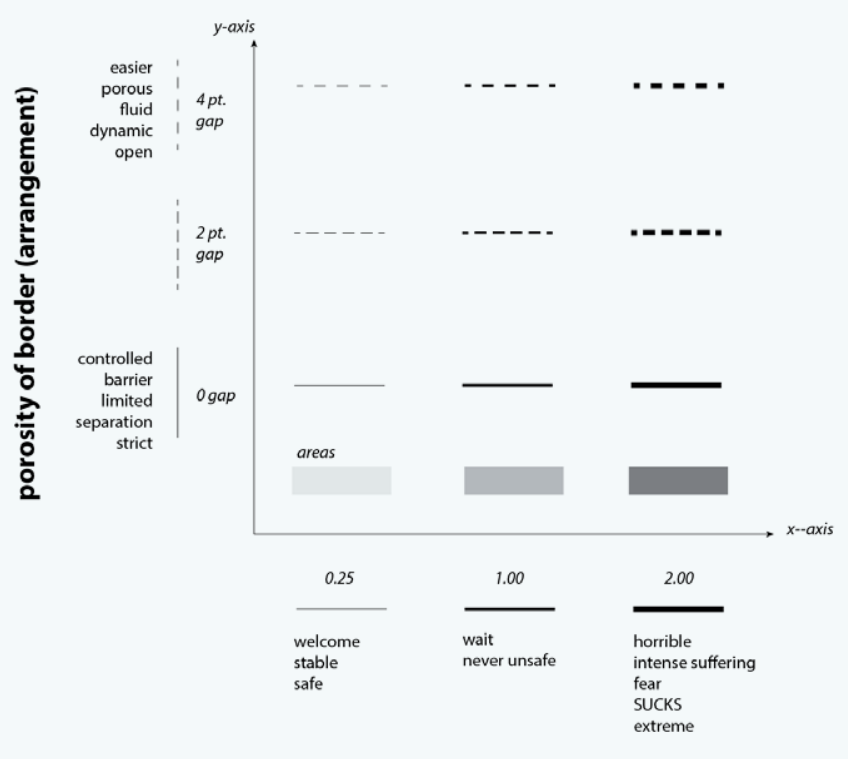

intensity of experience (size and value)

Figure 3. Bivariate line symbolization scheme applied to each border.

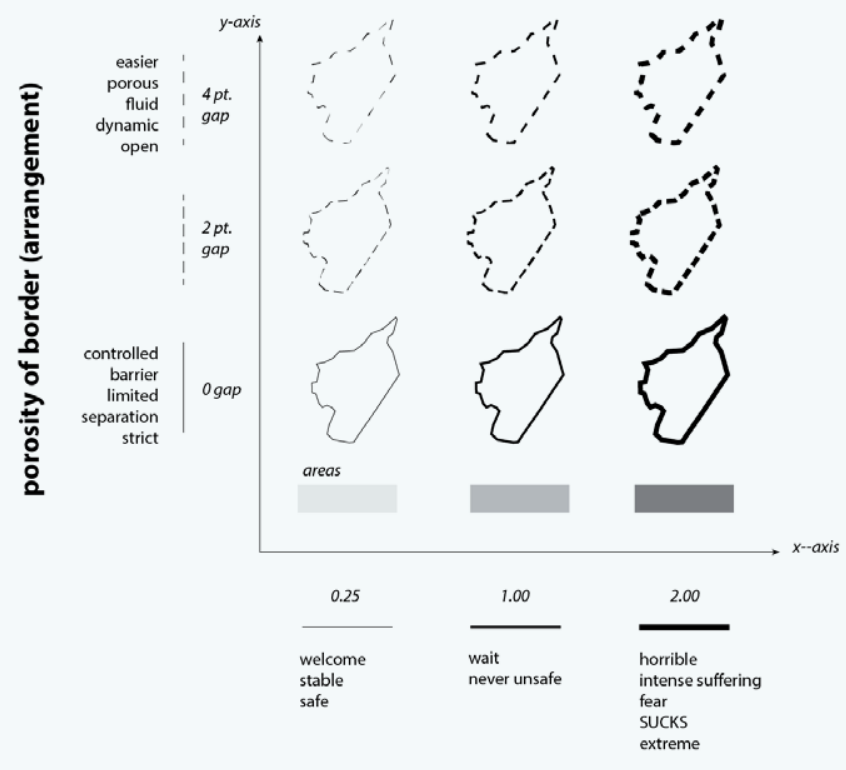

intensity of experience (size and value)

Figure 4. Bivariate line symbolization scheme applied to the Syrian border.

In the right panel, the name of the interviewee labels a point symbol (Figure 2, map element 3) at the start of the line in the lower right corner. This labeling strategy individualizes the point symbol. A thin vertical line extends from the point symbol to help organize the legend and narrative below. To the left of the dividing hairline, 
I identified each border by name (Figure 2, map element 4). To the right, I illustrated the border symbolization (Figure 2, map element 5). Together, the label and symbol make up the legend. Traditional borders are labeled in roman type and non-traditional and abstract borders are italicized. The border is symbolized to the right of the dividing hairline to connect the symbol to the border type. As the reader turns the page, the legend also gradually descends, moving the reader through each story sequentially as told by the interviewee.

The hairline also separates two narrative voices: the interviewee's voice (Figure 2, map element 6) and my own voice (Figure 2, map element 7 ). The interviewee's voice is identified to the right of this line in a black, sans serif typeface (Myriad Pro). An excerpt from the interviewee's story is placed here to guide the reader through the story. The excerpts on each page build the individual's story and create a narrative arc. At times the excerpts provide cohesion and at other times, they fragment the story. Either way, the story is told through the lens of the individual. My voice provides an outsider narrative that is positioned to the left of the hairline and written in a gray, serif typeface (Garamond). My voice does not carry the story and instead provides ancillary information to support or direct the map reader. The goal of my commentary is to focus the reader but not speak for the individual, minimizing my voice.

The sequence of maps and the layout of the page are important to the overall sequence of each border story. Many of my interviewees' stories were not linear in their telling. Because of this, I had to reinforce continuity and a sense of journey in other ways (see Box 1 for a summary). Each border experience, for example, is presented on its own page. By advancing through a digital PDF or flipping the page in a printed copy, the journey-as told by the interviewee-advances and moves forward. This narrative ordering focuses on the individual and carries the reader through the story as told by the teller.

The fluidity of the story is reinforced in the layout of the page. The reader begins in the center of the page and transitions to the right panel. The right panel is read as the reader moves down the page. The legend follows this same downward motion with each page turn. This linear timeline is constructed and driven by the interviewee. Last, the interviewee's narrative, along with my voice, helps piece
Each border experience is presented on its own page. As the reader advances through a digital PDF or flips the page in a printed copy, the individual carries the

1 reader through their story as they told it. This narrative ordering as opposed to chronological ordering focuses on the individual and how they told their own story.

The layout (Figure 2) guides the reader from the central 2 map to the right panel, where the reader moves down the panel, building context and narrative.

The legend (border name and symbol) in the lower

3 rightpanel shifts downward as the reader advances through the story.

Quotes from the individual are included in lower right panel to build narrative and context. The individual's

4 narrative carries the reader through the page. The mapmaker's voice, distinguished using a serif typeface, provides context and continuity when necessary.

Table 1. Cartographic techniques used to create a sense of linearity, journey, and narrative.

together the story and sequence of events. The interviewee's voice carries the reader through their narrative and journey, whereas, my voice "fills in the blanks" when necessary to help maintain some continuity and context.

\section{PERSONAL MAP WALKTHROUGH}

Here, I provide a brief walkthrough using some of Amal's maps (Figures 5-8). Though it does not cover Amal's story in its entirety, the walkthrough illustrates how this mapping technique works in practice. The rest of Amal's story, and additional mapped stories, can be found in the appended atlas, titled Borders: An Atlas of Syrian Border Stories.

The central map on the opening page of Amal's map series is blank and quiet, drawing your eye to the right panel (Figure 5). The locator map depicts Syria and highlights Aleppo, the city where Amal was previously living and working as a physician. Below is Amal's name. His name relates the forthcoming map series to Amal and his personal story. I briefly introduce Amal on the left side of the dividing hairline and Amal introduces himself on the right, describing his life at the beginning of the Syrian conflict. 
The next map page presents the first border-an abstract square space outlined in the center of the page-discussed by Amal (Figure 6). The border is placed in the middle of the map page to draw your attention. Familiarity with the map key or bivariate line symbolization scheme informs you that this abstract border is heavily experienced (symbolized with the thickness of the line) and rigid (symbolized with a solid line as opposed to a dashed line). The whitespace surrounding the border focuses your eye and illuminates the border as well as its label, "people did not trust hospitals." To fully understand this border, transition to the right panel for context and narration. The locator map shows the location of the border displayed in the central map.

This border is located in Homs and is related to a hospital. You are reminded of Amal and his experiences by his name, which labels a point at the terminus of the dividing hairline. Next, you can identify the border as a hospital, written to the left across from the border symbol on the right. "Hospital" is italicized, reminding you that this border is a non-traditional border. Amal's voice appears last, describing this border and his experiences. Here, he describes his call as a physician to help Syrians affected by the ongoing violence and notes the fear of seeking medical attention in

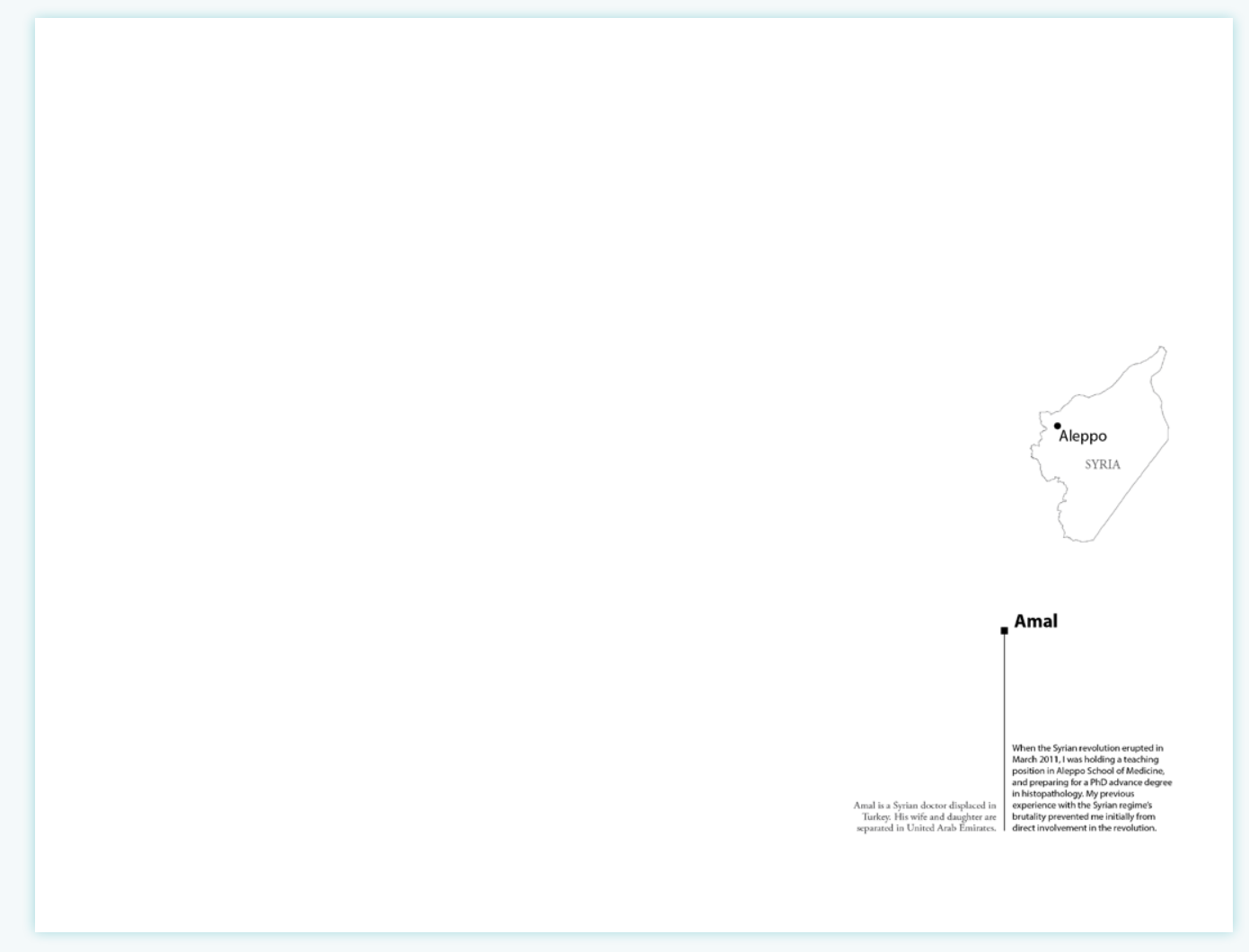

Figure 5. Opening page of Amal's map series.
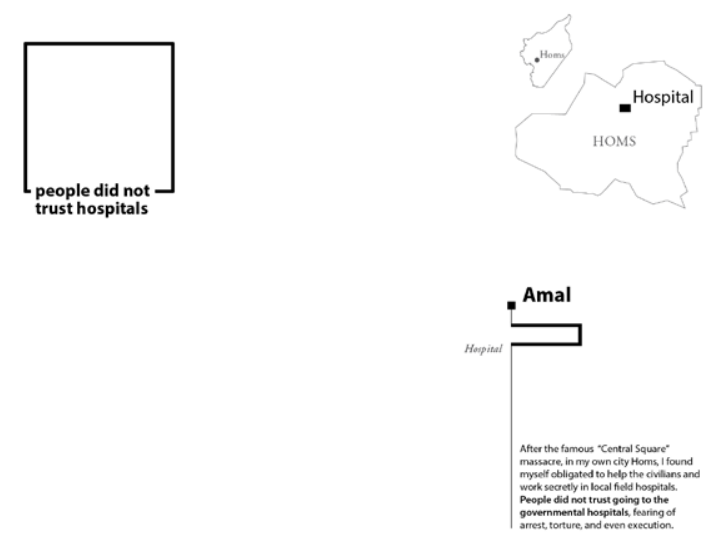

Figure 6. Second page of Amal's map series. 

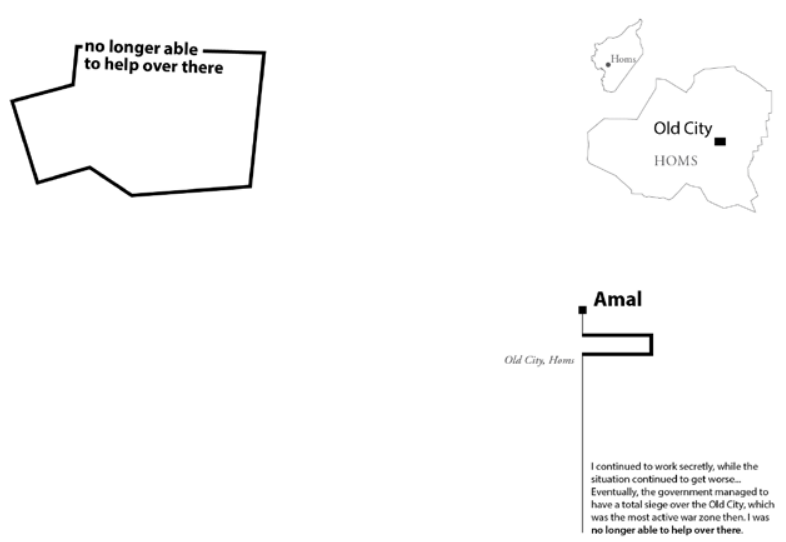

Figure 7. Third page in Amal's map series.
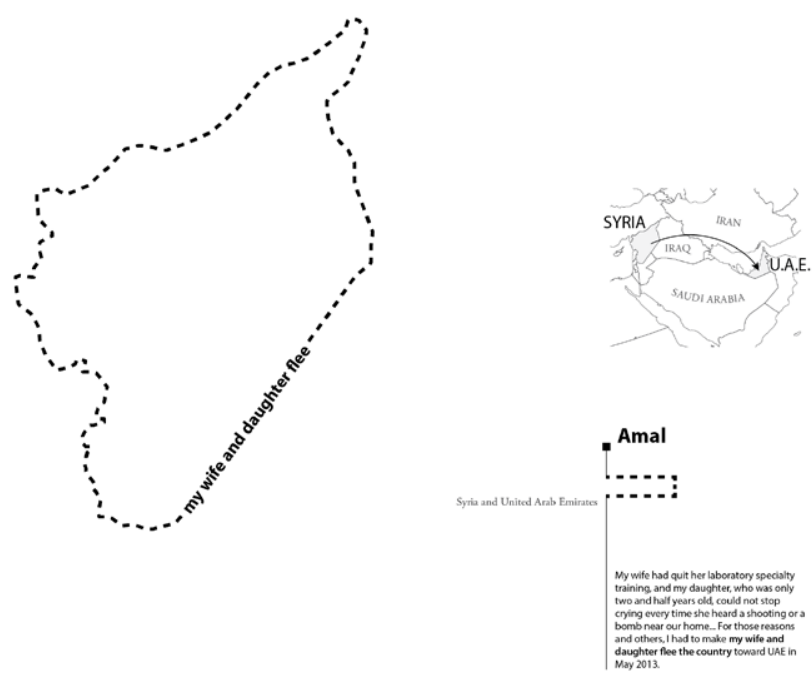

a government-run hospital. With the information provided in the right panel, the central map can be more easily interpreted and understood in the context of Amal's story.

As you move to the third map page, notice how the border changes shape, but the symbolization stays the same (Figure 7). The border label and content in the right panel also change. Beginning with the central map, we see a thick, solid borderline labeled this time with "no longer able to help over there." While the border symbolization is still the same, the experience written in the label is quite different. The locator map gives this border an identifiable location, the Old City in Homs, Syria. From the text below in the right panel, note that the border represents the Old City or the "most active war zone then" (Figure 7 , right panel). This region of Homs is a non-traditional border (italicized in the right panel) with a defined location. Amal then describes the total siege and government control surrounding the Old City. Amal's mobility is limited as he is excluded from the space. The border is perceived as strict and impermeable (solid) but is dangerous when experienced (thick). Again, Amal's voice carries you through the map page.

The fourth page in the map sequence presents a new polygon shape (Figure 8). 
Although irregular, this shape or border may be more familiar to you as it resembles an international boundary. This border is dissimilar to the previous two in other ways as well. The border is still thick and therefore intensely experienced; however, the line is also dashed. The dashed line elicits permeability and movement, unlike the previous two maps. Again, the border's label is unique to the border experience. This time it states, "my wife and daughter flee," which calls to mind movement. Returning to the right panel, you can further understand the border's geographical context given the locator map. The border is identified in roman type (not italicized) to denote the border as a traditional border representing Syria. Amal's voice continues to describe this border and his wife and daughter's passage through it.
Amal's story and experiences of borders continue through the remaining maps in the sequence. After "learning" how to read the maps with the available map keys, the repetition of the map layout design paces you through Amal's mapped story. Begin by examining the central map: its border symbolization and its label. What kind of feeling do you get when looking at the thickness, arrangement, and label of the line? Next, refer to the right panel, with the locator map for reference, and identify the border type. Is it traditional or non-traditional? Last, refer to my added narrative and Amal's voice at the bottom of the panel. While my voice provides contextual information, what is Amal telling you? His voice connects you to his story, his experiences, and the map. With these strategies, you can easily navigate Amal's story map along with other collected stories (Kelly 2015a; Kelly 2015b; Appendix).

\section{METHODS FOR AGGREGATED MAPS}

\section{AGGREGATED MAPS}

I BEGAN THINKING ABOUT AGGREGATION from the moment I began translating my seven interviews into map symbols. This cartographic translation, from the individual's story to the cartographer's symbol, aggregates the narrative by reducing the first-person account of the story to graphical marks. In cartographic practice, aggregation is a generalization technique that collapses multiple features from one dimension (e.g., points) into one feature from a higher dimension (e.g., polygons). I similarly use aggregation as a metaphor to demarcate the collapse of narrative detail within a single story or the collapse of multiple stories into a homoegenous, graphic form (Figure 9). Below, I detail my design process and present an aggregated map. In this section, I refer to two maps for each border: a small multiples map and an aggregated map (Figures 11 and 12, respectively).

After creating maps, as described in the previous section, for the stories of each of the interviewees, I began to explore aggregation as a means to collate these same stories into one graphic. First, I brainstormed several aggregating techniques, including merging multiple stories into one storyline, aggregating experiences with generalized symbols, collapsing features into different geometries (areas and lines to points), and quantifying experiences numerically. Next, I focused my attention on the individual story maps to explore common threads and points of differentiation. I began seeing overlap between the borders mentioned in each mapped story and started compiling all the individual maps sharing the same or similar borders. For example, 17 maps depicted the Syrian border and six maps illustrated the abstract space of the body. The same border could be described or experienced by the interviewees more than once in different ways. From this process, I developed nine border categories-Syria, SyrianLebanese, Syrian-Turkish, Syrian-Jordanian, United States, controlled areas, prison, Zaatari refugee camp, and the body-based on the geographic locations found in border stories, with the criteria that there had to be more than one map per category.



Figure 9. Aggregation is a generalization operator that collapses multiple features from one dimension into one feature with a different dimensionality. In a similar way, aggregation can also take place when a story and its personal details are translated into (often) homogeneous graphic symbols. 
I then made a small multiples layout for each category. I copied all 17 Syrian border maps, reduced their scale, and arranged them onto a single page (Figure 11), maintaining the border symbolization chosen in the individual maps. I used generalization in two ways. Because of the reduction in scale, I simplified the linework of each border. Next, I simplified the experiential label. The original Syrian border maps were labeled with a quote from the interviewee describing their experience of the border. I generalized this label and the experience by shortening the label to one or two words. Some shortened labels work quite well, while others are more ambiguous.

The small multiples layout aggregates individual experiences, yet maintains the voices of the individuals, albeit to a lesser extent than the individual maps. I included the name of the interviewee with their corresponding map to connect the reader to the individual. This technique allows the reader to compare varying line symbolization and experiences between each person and map. While the linework depicting two different experiences is sometimes symbolized in the same way, the experience label on each map is different and provides a glimpse into individual experiences.

The small multiples are a powerful way for the reader to simultaneously visualize and understand the similarities and differences between experiences of the same border. When displayed together, the maps provide a broader perspective. In the bottom corner, a text description briefly introduces the border depicted on the page to guide the reader through the maps as well as teach the reader about the technique (Figure 11).

To create the aggregated map (Figure 12), I examined the border symbolization used in each small multiples map showing a particular border location, beginning with the Syrian border. I used median values of the 17 Syrian border symbols to determine which bivariate line symbol to choose (Figure 3). The median line weight and gap size for the Syrian border was a 2 pt line with a 4 pt gap between each dash. I next turned to labeling the line. This step was a challenge because the borders in the individual maps are labeled with a direct quote from the interviewee's border experience. Aggregating individual voices into one was an impossible goal for a couple of reasons. First, I did not want to prioritize one border experience over another. Second, I could not summarize the border experiences in words without aggregating even further. I opted instead to label the line with the border's name (for example, Lebanon) using a serif typeface (Garamond) in gray. These type specifications, similar to those used in the individual maps, designate the text as my voice, that of the cartographer. This technique is problematic because I completely removed the experiential labels. However, by switching the typeface, I demarcate my position as the aggregator. Although this labeling technique is a compromise, it forces the cartographer to be accountable. It also expands border identification and labeling to non-traditional borders. Many non-traditional borders are not recognized as borders at all, and without a label, they are silenced. A simple label brings these borders to the forefront and makes them visible on the page.

For the aggregated maps, I used a layout similar to the one used for the individual maps (Figure 2) with a few minor variations. I used a locator map to ground the reader and provide geographic context. The locator map uses conventional techniques that allow the reader to compare the aggregated map and symbolization with conventional techniques.

Below the locator is a square point symbol. In the aggregated map, this symbol is labeled "Interviewees" to acknowledge their collective experiences and perspectives. The point symbol is attached to a dividing line below. As in the individual maps, I identified each border by name (left side) and by symbol (right side) across the dividing line, connecting it to the central map. Traditional borders such as the Syrian border are denoted using roman type, and non-traditional borders such as the body are differentiated with italics. In contrast to the individual maps, I also provided the aggregated line symbolization specifications to directly identify the median values assigned to the border symbols.

Throughout the maps in the atlas, the dividing line separates voice, with my voice to the left (an outsider perspective written in a grey serif typeface) and the voice of the interviewees to the right (a first-hand account of border crossings written in a black sans serif typeface). Because the stories are aggregated, I did not use the interviewees' voices to guide the reader because I did not want to prioritize one experience over another. Instead, I relied on my voice to summarize their stories and provide an idea of how the border can be experienced in various ways. 
This pairing of small multiples to show common difference, and an aggregated map to show a generalized border story, was then repeated for each border category. The small multiples layout is strategically displayed first to expose the reader an overview of all of the experiences of one border type. The small multiples and the written narrative help the reader interpret the second map (the aggregated map), its symbolization, and the varying experiences embedded in each border. Together, they demonstrate differentiation as well as similarity and parallels between border experiences.

\section{AGGREGATED MAP WALKTHROUGH}

Here, I provide a brief walkthrough of the aggregated map series (Figures 10-12). This walkthrough does not cover the aggregated map series in its entirety but should be used to help guide you through the remaining pages. Similar to the individual maps, the opening page of the aggregated map series is sparse, with the exception of the right panel (Figure 10). Look to the right panel for geographical context provided in the locator map and the introductory text below.

The following pages in the map sequence alternate between two map types: the small multiples and aggregated maps. Each border discussed in the interviews is presented using both map types, beginning with the Syrian border (Figure 11). The small multiples allow you to compare and contrast individual border experiences. This is an intersectional approach to mapping borders, which recognizes the similarities and discontinuities between border

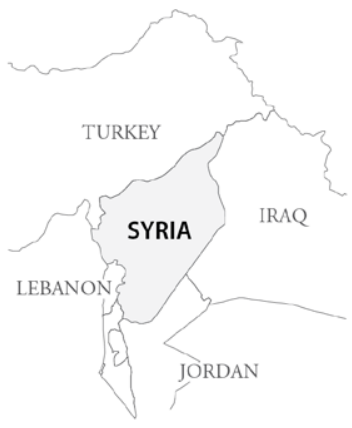

Figure 10. Opening page of aggregated map series. 




Figure 11. Small multiples on the second page in the aggregated map series. The small multiples provide a visual comparison and illustrate the complexities, similarities, and intersectional differences between individual experiences. The small multiples are paired with the aggregated map (Figure 12) to simultaneously recognize individuals and multiplicity of experiences in aggregation.

experiences and revised map symbolization. Each border is uniquely symbolized and labeled. Adiba's perspective in the top-right corner is symbolized as a thin, dashed line and is labeled "women." This map is very different than Eva's border, symbolized in the bottom-left corner with a thick and impenetrable line related directly to the lack of resources to leave the country.

Next, examine the aggregated map of Syria (Figure 12). Notice the layout is similar to that of the individual maps. Focus initially on the central map: its border symbolization and its label. Refer to the right panel for locational information, the summarized symbolization specifications, and contextual information provided by my voice at the bottom of the dividing hairline. The aggregated map collapses the individual experiences of particular borders into one map, a useful, and at times necessary, technique.

With this strategy, you can easily navigate the remaining pages of the aggregated map sequence available in the Appendix. The repetition of the map layout paces you through collective border experiences. 

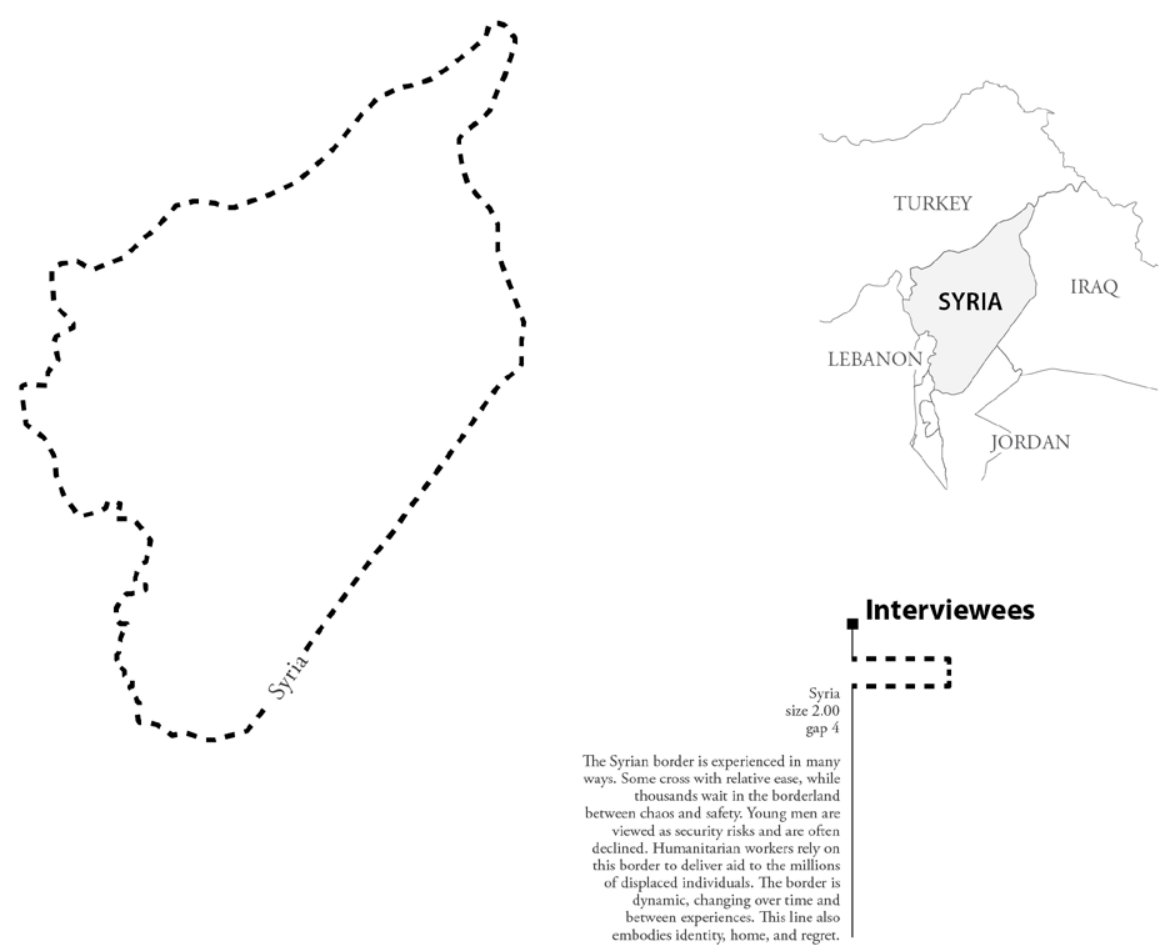

Figure 12. Aggregated map on the third page of aggregated map series. When paired with the small multiples (Figure 11), the aggregated map is meant to show an overview that typifies the border symbolization in the small multiples. Similar to Mohanty's (2003, 503) "common difference," this contrasting pairing simultaneously recognizes the individual and the multiplicity of experiences in aggregation.

\section{DISCUSSION}

I DEVELOPED AN ALTERNATIVE mapping technique to open new possibilities for border symbolization, guided by feminist theory and individual experiences. My goal was to enhance the cartographic presentation of the stories of Syrian refugee border crossings described by Amal and my six additional interviewees, to more fully reflect their border experiences. To do this, I relied on my primary source interviews and relevant literature in the fields of feminist theory and border studies to guide my iterative mapping process. Here, I discuss the successes and limitations of the maps in light of this background material, beginning with borders.

\section{BORDERS DISCUSSION}

Borders are central to the discussion of Syrian experiences and the ongoing conflict. From leaving one's neighborhood, to being trapped in one's home, to leaving the country, Amal and my other interviewees identified and highlighted different types of borders they encountered. These borders included formal borders such as the Turkish border and informal borders such as regime-controlled neighborhoods, rigid and consequential. Less obvious borders, such Amal's body when he was physically injured, were also made visible through mapping. Borders are the 

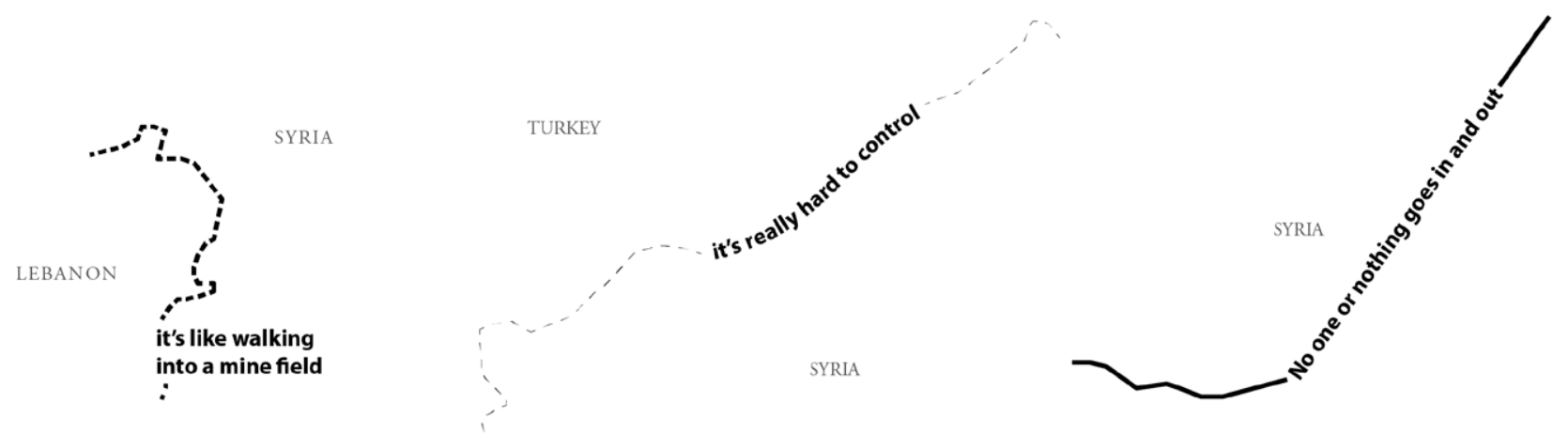

JORDAN

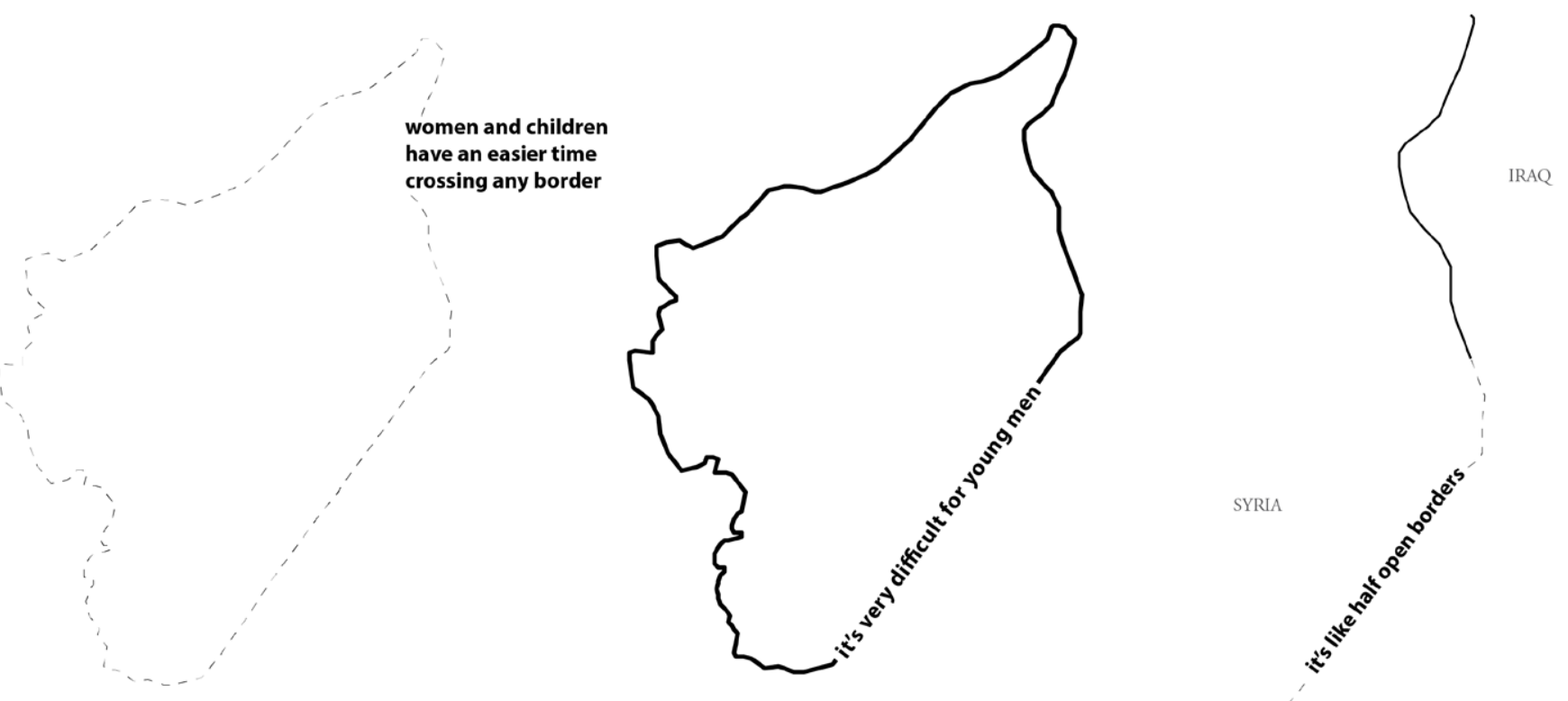

Figure 13. Differing line symbolization based on Mohammed's and Adiba's description of each border.

central focus of this feminist mapping project and the main focus within each map layout.

Borders and cartography have a rich, interwoven history (Black 1997). Cartographers' emphasis and reliance on symbolizing traditional borders reinforces the territorial trap that all state boundaries are fixed, homogeneous, and equal containers of the state (Agnew 1994 and 2003). Borders are neither solid, equal, static, nor rigid, nor are they experienced in the same ways. My alternative mapping technique aims to dispose of this state-centrism by removing homogeneous symbolization. I developed the bivariate line symbolization scheme seen in Figures 3 and 4 to reflect these dissimilarities and discontinuities.

Mohammed is another person I interviewed and asked about Syria's borders with neighboring countries. He is an activist and relocated refugee living in the United States. Given his personal experience and professional expertise working in humanitarian relief, he described the SyrianTurkish border as relatively open and "hard to control" and the Syrian-Iraqi border as "half open" and "fairly controlling" (Figure 13 and Appendix). In contrast, he described Syria's border with Lebanon as "a mine field" and stated that "no one or nothing goes in and out" (Figure 13 and Appendix).

Another interviewee, Adiba, noted that different groups experience Syria's borders in different ways (see Figure 13 for examples). For example, women with children generally have an easier time crossing all of Syria's borders. In contrast, men, particularly young men, have a more difficult time crossing because they are considered high-risk or are called to serve the military. In summary, Syria's borders 
vary drastically at both the geopolitical and personal levels. Mohammed and Adiba's stories, and the bivariate symbolization scheme, illustrate each border accordingly (Figure 13). Doing so "untraps" international borders and the map cartographically.

Similar to the work of Guidice and Guibilaro (2015) and Yuval-Davis and Stoetzler (2002), my interviews uncovered hidden narratives and complexities of individual border experiences. I expanded this work by translating these experiences into symbols and marks on the map, challenging cartographic conventions. With a few exceptions, I chose lines to depict borders in the central maps because of their familiarity and usefulness to the reader (Guidice and Giubilaro 2015, 81). My interviewees frequently referred to their experienced borders as lines or barriers. Early map drafts experimented with dimensionality, symbolization,

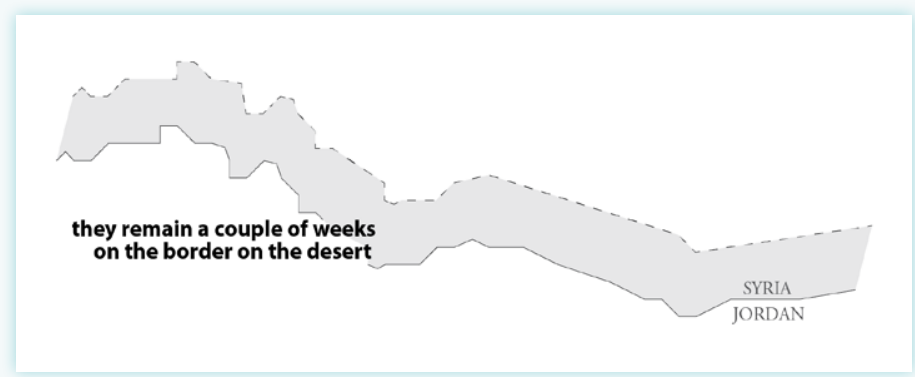

Figure 14. Borderland or area symbolization based on Fateh and Baraq's description of Syrian-Jordanian border.

Figure 15. Non-traditional borders without specified geographic coordinates are often left unmapped (in this example, Amal's body). The border is made visible with an abstract square space and, like traditional borders such as Syria's border with Turkey, it is symbolized using the bivariate symbolization scheme in Figure 3. and abstraction, but I kept returning to the line. I then explored, reimagined, and reshaped conventional line symbolization, embedding new meanings to reveal the possibilities of mapping the intensity of experience and porosity of the border simultaneously. The bivariate line symbolization scheme adopted in this atlas highlights nuanced and varied experiences. Although cartographically subjective (like every design decision), my symbolization choices were guided directly by individuals' border stories. Excerpts from my interviews were placed along the $\mathrm{x}$-axis and y-axis of Figures 3 and 4 to classify each border symbol. The symbol choice and added experiential border labels provide a vivid encounter with Amal's story and border experiences.

Borders are "no longer simply lines on the map" (Rumford 2006, 161-162); they are borderland regions or critical zones of hybridity, confluence, exchange, and connectivity (Anzaldúa 1987; Rumford 2006). To reflect this graphically, I expanded the dimension of the lines to areas when described by the interviewee. For example, Fateh and Baraq described Syria's border with Jordan as an area with over 1,000 refugees waiting in limbo for clear passage. Instead of lines, I re-envisioned these borderlands using polygons to denote areas. Like the lines, I used arrangement to show porosity around the bounds of the border area. I then added changes in value in the intervening space to show intensity of experience (see areas in Figures 3 and 14). The darker the area, the more intense the borderland experience; lighter areas correspond to less intense experiences.

In addition to traditional borders, I also mapped non-traditional borders or contact spaces (Antonsich 2011; Näre 2014). Many of these non-traditional borders were identified in my interviews. Amal, for example, recognized the critical societal barriers between hospitals run by the Assad regime and the general public's fear of using the facility. Other non-traditional divisions include but are not limited to the body, the home, and controlled areas such as cities or neighborhoods.

One of the most important differences between traditional and non-traditional borders is their geographic "exactness." Traditional borders, such as Syria's international boundary, or the Damascus city limits, have specific geographic coordinates available for download and display. In contrast, non-traditional borders do not always have a precise location and a corresponding digital file. Borders 
or other features that lack geographic information are generally not mapped, rendering them invisible in the map (Kelly 2015b). For borders with unspecified coordinates, I used squares to show undefined, abstract space (Figure 15). This technique revealed non-traditional borders that would otherwise go unseen. By treating non-traditional borders the same way as I would a traditional border, I identified, symbolized, and equalized the importance of all borders and border experiences.

\section{FEMINIST THEORY DISCUSSION}

Feminist theory played a significant role throughout the design process. I sought to ingrain the theoretical concepts of the body, reflexivity, intersectionality, and transformation into the maps (see Table 2 for a summary). Although I could not fully translate each concept into the maps, these areas of literature are critical to re-envisioning the map, its symbols, and its overall purpose.

While mapping, I focused on the simplest and most direct definition of the body: the body as "the geography closest in" (Rich 2003, 212). This definition allowed me to examine the stories told by my seven interviewees, looking for these intimate geographies, including experiences (Amal's physical injury), perspectives (Amal's recognition of public distrust of hospitals), and feelings (Amal's internal struggle treating both sides of the conflict).

\footnotetext{
Theoretical Concepts Body

Intersectionality

Transformation

Transformation

Reflexivity

\section{Cartographic Design Decisions}

- Incorporate the intimate geographies of bodily experiences, geographies often unmapped

- Symbolize bodily borders (and other non-traditional borders) as bounded space using abstract square shapes

- Symbolize bodily borders in terms of intensity of experience and porosity using a bivariate symbolization scheme

- Place individuals and their experiences in the center of the page using border symbolization

- Label borders based on individuals' experiences to embody the "line"

- Reveal and emphasize individual bodies by labeling a point feature in the right panel

- Rely on the individual's voice in the border label and right panel to carry the narrative

- Create individual maps for each person and all border experiences, traditional and non-traditional

- Illustrate the intersectional identities and differing experiences of each individual using the bivariate line symbolization, experiential labeling, and narrative text

- Recognize the similarities and differences (common difference) between individuals by utilizing a consistent layout and symbolization scheme

- Show common difference and experiences of similar geographies through small multiples and an aggregate map pairing (Figures 12-13)

- Expand border symbolization by embedding additional levels of meaning (intensity of experience and porosity) into the line

- Extend border symbolization across lines and polygons

- Include non-traditional borders generally silenced by conventional mapping techniques

- Include individual bodily borders as abstract square spaces

- Place border labels and added narrative pieces

- Open the conversation with the reader and personally connect with the reader by providing a map walkthrough to guide the reader through the maps and their interpretation

- Include positionality statement in text (see reflexivity statement in the Appendix) and map form

- Demonstrate the reflexivity of the map itself through iterative mapping, transparent process, and documentation

- Separate the cartographer's voice from the individual's voice using serif and sans serif type styles, respectively

- Encourage other cartographers to be reflexive in their own work
}

Table 2. Summary of feminist theoretical concepts and their cartographic implementation in the map. 
Although attempts have been made in the last ten years to map personal and emotional geographies (Griffin and McQuoid 2012), personal geographies and the individual body are often not mapped in Western media (Kelly 2015b). As cartographers, we have a tendency to aggregate bodies (Sprunk 2010; Kelly 2015b). Contemporary media frequently aggregate bodies into points, lines, or areas, neglecting the subjective, personal experiences of those involved (Sprunk 2010, 289). Individual experiences are lost, while a generalized reference or thematic map remains.

Valentine $(1999,331)$ calls the body a "tactile" bounded space that is "always sensing and actively engaging with itself (the inside) and the world (the outside)." Because of the complexity of the body and differences between bodies, I choose the square as an abstract space (not a point or line) to show this intimate boundary (Figure 15). I then symbolized these body squares or non-traditional borders using the bivariate line symbolization scheme found in Figure 3. Literature related to the body and subjective experience helped inform the development of this symbolization scheme.

Why the square? An abstract shape was imperative because an iconic symbol would present the body in a very prescribed way. The two icons on the right of Figure 16 depict the body in a conventional, heteronormative way. These icons also presume able-bodied figures and neglect individual identities and subjectivities. The square was a deliberate choice because it shows the body as a bounded area or space. In part, the square was also an aesthetic choice. A circle or triangle could just as easily have been assigned as the body, but the square looks and feels like the built environment or a built border wall.

The artist Zarina also uses a square in her piece "House with Four Walls" (Samantrai 2004). She notes that the square or char diwari (four walls) is a "complicated idea because it is used in so many contexts" (Samantrai 2004, 180). Four walls can depict the home but can also be embodied.
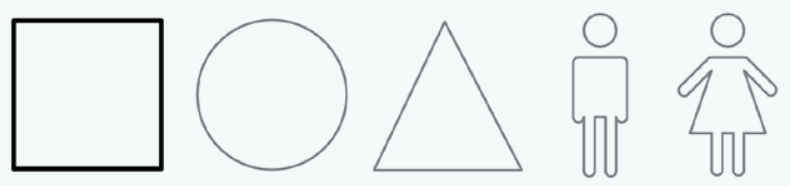

Figure 16. Various body icons.
In addition, the four lines making up the square must be understood by the reader based on the "walls of his/ her own experience" (Samantrai 2004, 184). The square is malleable and can be stretched to fit non-specific locations in addition to the body. This is why all non-traditional borders, including the body, are symbolized as abstract squares. The size of the square remains constant to further equalize each border experience. Scaled squares would necessitate a hierarchal or ordinal structure that would prioritize some experiences over others.

I graphically expressed the body in other ways too. As mentioned, each border was labeled based on an excerpt from the individual's story. Each border embodies the individual and his or her border experience by placing an interview excerpt directly on the line. Although excerpts were subjectively chosen by the cartographer, this technique makes the body visible within each border in the center of each map page. I also used a point symbol at the beginning of the dividing hairline to represent the individual telling the story (Figure 2, map element 3). I focused attention on the body by labeling the point symbol with the individual's name. The point symbol and its corresponding name are visible on each map page. In doing so, the reader is constantly reminded of the individual telling the story. This technique connects the central map and the text to the storyteller. The central map and voice belong to the experience and perspectives of the individual, the body.

Individual identities are complex, messy, overlapping, and do not always fit into tidy categories such as Syrian, man, or physician (D'Ignazio and Klein 2016). In each interview, I focused on intersectionality or the "complexities, singularities, and interconnections" between individuals (Mohanty 2003, 523; Crenshaw 1991; Collins 2015). Intersectionality is illustrated cartographically in several ways. First, by making individual maps similar to Amal's for multiple interviewees, I was able to introduce each interviewee along with relevant personal details and symbolize borders specific to the individual. Each border is symbolized using the bivariate line symbolization scheme seen in Figures 3 and 4. As such, the individual's voice and experience are embedded within the line. Second, the experiential labels and narrative text in the lower-right panel expand the reader's understanding of the individual's border experience. The individual's identity and intersectionality are critical to understanding each border experience. As readers sequence through the maps, they continue to learn about the complexities of each individual and their 
stories through border symbols, border labels, and narrative text.

Generalization and aggregation are not completely avoided. For example, I used a standardized layout and a prescribed symbolization scheme for each individual map. These techniques are useful for producing clean and consistent design, but they limit the expression of unique identities and intersectionality. I relied on "common difference" to balance the complexities of individuals with commonality between individuals (Mohanty 2003, 503). The theoretical framework of common difference was useful as I created nuanced, intersectional, yet consistent symbolization. In sum, it's important to acknowledge the effects of generalization and aggregation and work towards alternatives that recognize common difference.

The power of this approach is strikingly apparent when the same border experienced or described by several interviewees is presented in the small multiples layout. Figure 11-small multiples of the Syrian border-shows the same line re-interpreted through several individual experiences of a particular border. In it, six of the 17 maps of Syria symbolize the border as a thick solid line (an impermeable, yet heavily experienced border). On the other hand, each border experience and label is subjective and is therefore, individual. The solid, thick border described above can be contrasted with the thin, dashed symbol in the upper-right frame. The individuals in each map come from various walks of life. Some remain in Syria's neighboring countries; others are working as activists further abroad in the United States. They are, however, connected by having experienced the same border. In addition, some individuals experienced the Syrian border in similar ways. Side by side representations or small multiples demonstrate simultaneously the intersectional differences as well as connectedness between shared or similar experiences and geographies.

The maps developed in this study are produced by a transformative mapping approach that deconstructs and redefines the map and border symbolization by focusing on experiences (Cresswell 2013; D'Ignazio and Klein 2016). My approach expands border representation beyond international boundaries by incorporating non-traditional borders and borders lacking precise locations. In addition, my maps re-envision borders with voice and subjective experience.
This approach deconstructs and rethinks the power and silencing effects embedded within conventional border representation (Cresswell 2013; D'Ignazio and Klein 2016).

Scale, certainty, and anonymity of my interviewees were significant challenges to address when designing my transformative approach. My primary goal was to prioritize and enhance the intimacy of individual borders and experiences. In some cases, like in the map of the entire Syrian border (Figure 8), the precise location where Amal's family crossed the border was unknown - the location was either a detail left out in conversation with my interviewee or was left intentionally undisclosed for anonymity and safety purposes. To accommodate this uncertainty and capture Amal's experience and separation from his family, I symbolized the entire Syrian border. This, however, produced an unavoidable scale tension between intimate individual experiences and the geography of the border. When locational and contextual details were available, I was able to incorporate them cartographically to more precisely portray the border and border experiences.

Finally, transformation of the mapped space relies on readers' interpretation of the line symbolization, experiential labels, and narratives. This technique calls the reader to each border experience and provides the necessary legends (Figure 2-4), tools (map walkthroughs), and questions to aid interpretation. However, the story really takes shape by inviting the map reader into a conversation (Pearce 2008).

Reflexivity in relationship to feminist research asks the researcher to recognize their positionality, subjectivities, and biases (England 1994). The same approach applies to cartographers and mapping. From the beginning, I needed to remain aware of my own positionality as an outsider to the Syrian refugee crisis. This allowed me to recognize the limits of my perspective as well as the limitations of my mapping effort (Appendix, Positionality section). Even with the best intentions, my cartographic decisions will never truly capture Amal's or the other interviewees' border experiences and perspectives. Documenting positionality and acknowledging shortcomings - available in the Appendix - is crucial to mapping experiences and stories other than your own, especially those that include traumatic, personal, and ongoing situations.

Reflexivity can be practiced cartographically through an iterative and self-aware mapping process. Through each mapping iteration, I needed to remain aware of my 
position as well as the impacts of my maps and symbol choices. What's working? What power dynamics are at play? What's not working and why? As a cartographer trained in Western mapping traditions, I began mapping with conventional techniques and then worked forward by continuously questioning and editing the map. I documented my process and symbolization explorations along the way to track the technique's trajectory. I sought feedback from peers and colleagues throughout and finally, I formally documented my process.

Transparency, iteration, and documentation of process were instrumental in maintaining my own reflectivity as well as the reflexivity of the maps (i.e., where they came from and how they came into being). I struggled, for example, with narrative text because I wanted to limit my narrative input and concentrate solely on mapping the story at hand. In the end, my voice was necessary at times to supplement the narrative because the map reader wasn't present during my interviews with Amal and others involved with the Syrian conflict. I needed to fill in the blanks and guide the reader. In addition, I was forced to recognize that my interpretations were changing and generalizing each story. By acknowledging my changing positionality throughout the process, I was able to see for myself the necessity and value of incorporating both voices.

While discernible and expected in feminist academic writing, cartographic reflexivity is often less visible in the map itself. How do cartographers demonstrate reflexivity with graphic marks on the map page? Similar to Pearce (2008), I integrated but separated my voice (the cartographer) from my interviewees' voices both in space on the map page and in style-serif for my voice on the left and sans serif for the interviewee's on the right of the dividing hairline (Figure 2, map elements 6 and 7). Cartographic reflexivity, however, is an area of research begging further questioning and conscientious undertaking by all cartographers.

\section{CARTOGRAPHIC DESIGN DISCUSSION}

This study developed from my dissatisfaction with conventional mapping techniques, particularly the techniques used by Western news media outlets, which push borders into the background and remove the body and personal experiences (Kelly 2015b). It must be noted, however, that my dissatisfaction derives from applying a specific theoretical lens, a lens focused on border literature, feminist theory, and critical mapping practices. As such, I recognize that the intentions of other cartographers portraying border experiences and the functions of their maps are likely different than my own.

Aside from providing a description and walkthrough of Amal's story and my alternative mapping technique, this study did not take the experience of the map reader into account. While beyond the scope of this paper, this limitation is valid and points to future research directions. How do map readers perceive and understand unconventional mapping techniques? How do unconventional mapping techniques become conventional, familiar, and understood

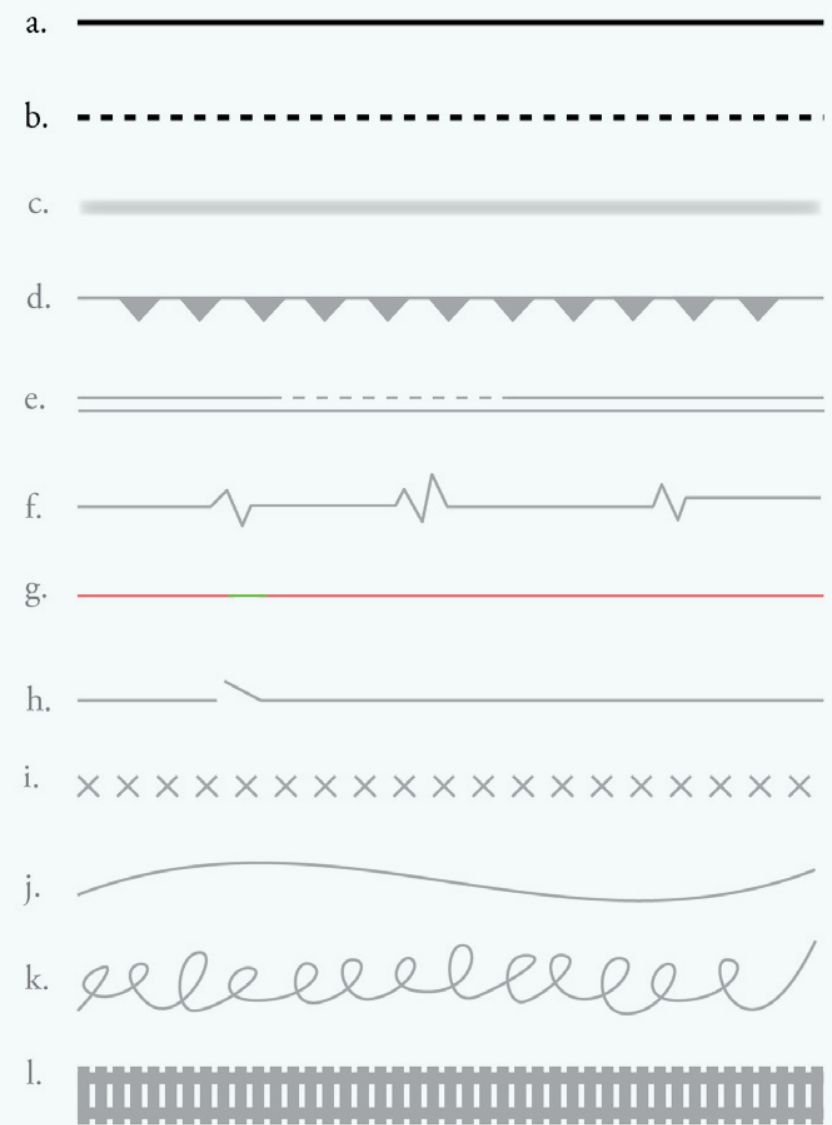

Figure 17. The visual variables size (a) and arrangement (b) are just two design possibilities. Alternatives include blurred lines to show uncertainty (c), triangle shapes to depict directionality (d), double lines to illustrate two border encounters (e), and associative lines that use a heart monitor as a metaphor to show physiological response to border lines (f). Additional design strategies include the use of hue to demonstrate access (stop/ go) or emotion (positive/negative) (g), and a range of associative and iconic depictions like a door (h), a series of " $x$ " characters (i), wavy lines (i), barbed wire (k), and fencing (I). 
by the map reader? User studies would be an appropriate next step to understand the usability of this technique.

Furthermore, my feminist mapping technique is just one alternative; many static and interactive design opportunities are possible. I focused on two visual variables-size and arrangement - in my border symbolization. These are just two of several visual variables or cartographic buildings blocks used to encode map symbols with perceivable meaning (Slocum et al. 2009; Figure 17). Size and arrangement are, at times, limiting; both, for example, lack a clear depiction of directionality (is the individual enclosed or excluded, and in what direction are they moving?). Figure 18 suggests alternative designs using labeling and symbolization techniques that suggest varying accessibility and the position (inside/outside) of the individual. In the aggregated maps in this atlas, borders like the SyrianLebanese border are presented as one section of the overall Syrian border, in order to recognize variations. I completed a sketch mapping study (Kelly 2016) which proactively reassembled these border symbols into a map mosaic to geographically locate experiential differences and alternative symbolization along Syria's borders (Figure 19). This mosaic further explores the breadth of visual variables for border symbolization (Kelly 2016). Additional analysis of the visual variables, as well as the dimensionality (points, lines, and polygons) and directionality of border symbols and labels, is needed to truly rethink all the possibilities of border representation. Last, I relied on four cartographic techniques for emphasizing the narrative chronology in this atlas (described in Table 1), but there are a variety of techniques that could have been incorporated, like an accumulation of borders or an extension of the timeline (Figures 20 and 21).

Finally, my interviews with Amal and other Syrians and humanitarian workers were integral in the development of my alternative mapping technique. Due to time constraints and the scope of this project, they were unable to participate further. Going forward, I plan to increase the involvement of interviewees in the mapping process through participant mapping and by iterations of formal feedback. Additional interviewees across varying case studies would also strengthen the utility and applicability of this cartographic technique across all border scenarios.

\section{CONCLUSION}

The Syrian Refugee crisis is one of the most critical and underfunded humanitarian crises in recent history. As of November 2019, the conflict continues into its eighth year due to the sheer complexity of the conflict. As nearly 5.4 million have fled across borders within the region and further abroad into the European Union, host countries and cities struggle to cope with the influx of Syrians (UNHCR 2018). Another 6.3 million Syrians are internally displaced amidst major cities under siege and in complete ruin (UNHCR 2017). As the crisis continues to unfold, and as Syria eventually rebuilds, the needs in the region will only increase.

I have developed an alternative mapping technique to open new possibilities for border symbolization, rooted in individual experiences and feminist theory. My goal was to enhance the stories of Syrian refugee border crossings as described by Amal and six other interviewees (Appendix), and to more fully reflect and visualize their experiences and intersectionality cartographically. To do this, I relied on my primary source interviews and relevant literature in the fields of border studies and feminist theory to guide my iterative mapping process.

This project contributes to and expands the field of cartography by integrating border studies and feminist theory into mapping. Using this interdisciplinary lens, I focused on the symbolization of borders and rethought "the line" as a new narrative mapping technique that emphasizes experience. My final mapping technique complements and broadens contemporary journalistic mapping and supplements story and narrative mapping literature and practices. 


\section{Collectively Mapping Borders}

Meghan Kelly

$$
\text { TMRKEY }
$$


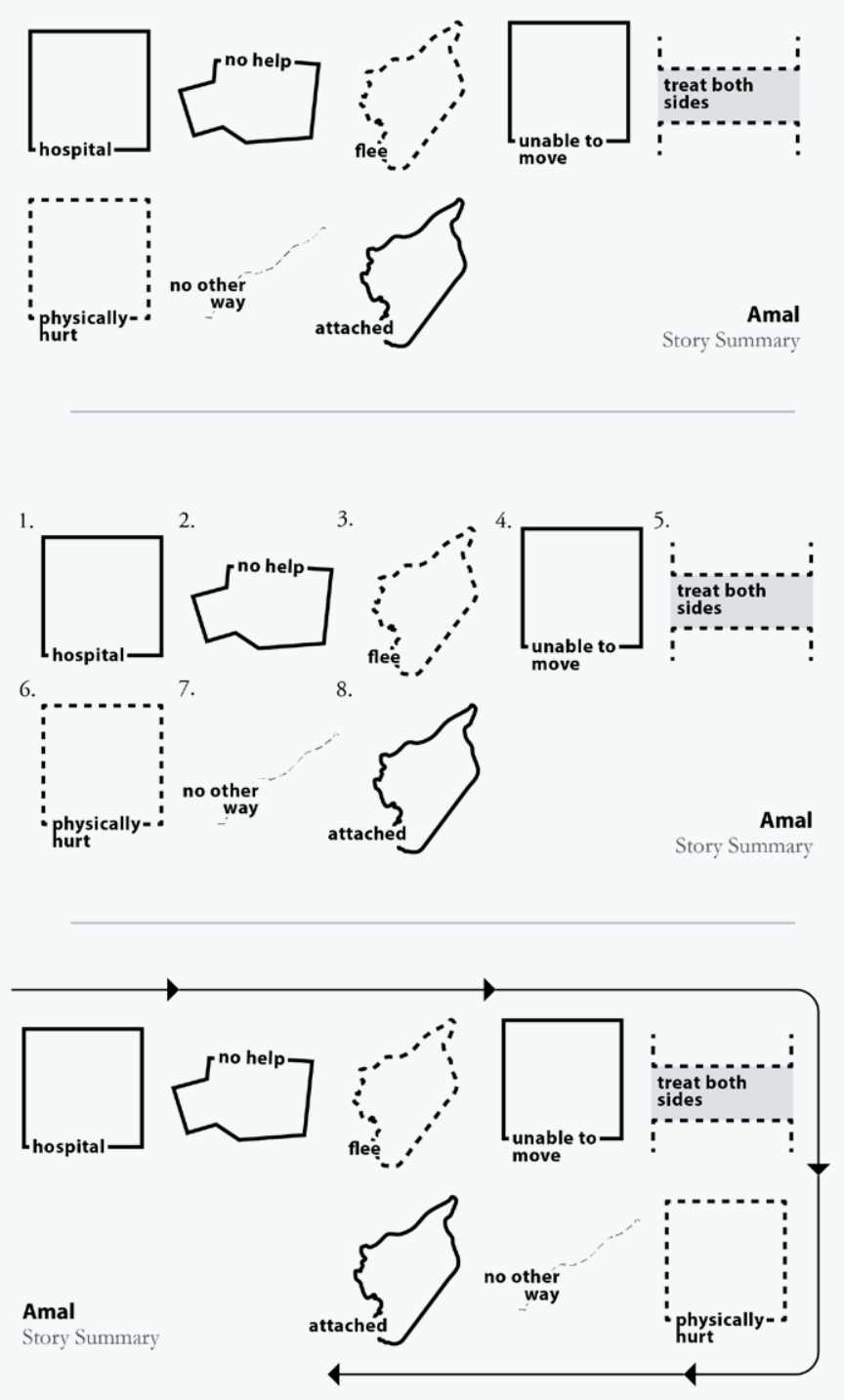

Figure 20. Possible design solutions to support linear narration can take various forms, including locational sequencing, numbering, and directional arrows.

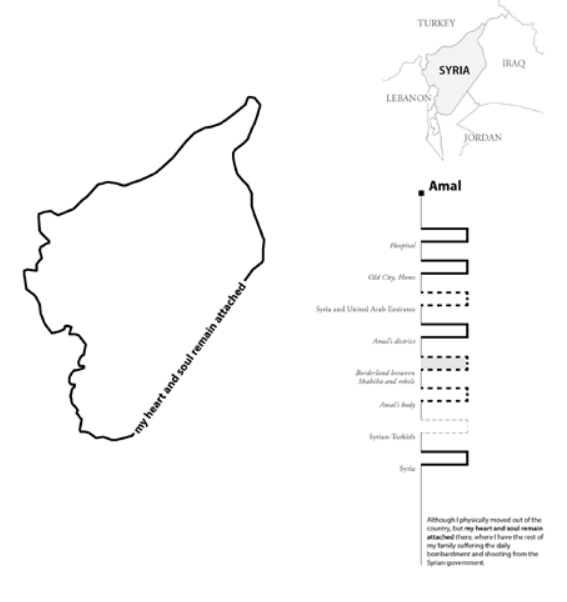

Figure 21. Possible design solution to show linear narrative and sequence of border experiences by accumulating border experiences within the timeline.

As mentioned, my technique is just one alternative approach. While imperfect, it does nudge feminist cartographies and border symbolization forward by questioning and transforming our conventional mapping practices. Similar to Danny Dorling's take on using cartograms to map census data, the "main disadvantage is that they [this technique] are unfamiliar, but we do not learn from familiarity" (1993, 171). By focusing on new, unfamiliar border symbolization, I expand and transform our cartographic vocabulary to reflect the subjective experiences of those crossing each border. It is my hope that this expanded vocabulary gives Syrians a geographic voice as yet unavailable to them through conventional cartographic techniques and homogeneous border symbolization.

\section{REFERENCES}

Agnew, John. 1994. "The Territorial Trap: The

Geographical Assumptions of International Relations

Theory." Review of International Political Economy 1 (1): 53-80. https://doi.org/10.1080/09692299408434268.

\section{MD: Rowman \& Littlefield Publishers.}

Antonsich, Marco. 2011. "Rethinking Territory." Progress in Human Geography 35 (3): 422-425. https://doi. org/10.1177/0309132510385619.
Anzaldúa, Gloria. 1987. Borderlands-La Frontera: The New Mestiza. San Francisco: Aunt Lute Books.

Ashkenas, Jeremy, Archie Tse, Derek Watkins, and Karen Yourish. 2014. "A Rogue State Along Two Rivers: How ISIS Came to Control Large Portions of Syria and Iraq." The New York Times. Accessed January 5, 2018. https://www.nytimes.com/ interactive/2014/07/03/world/middleeast/syria-iraqisis-rogue-state-along-two-rivers.html. 
Black, Jeremy. 1997. Maps and Politics. Chicago: University of Chicago Press.

Caquard, Sébastien. 2011. "Cartography I: Mapping Narrative Cartography." Progress in Human Geography 37 (1): 135-144. https://doi. org/10.1177/0309132511423796.

Caquard, Sébastien, and William Cartwright. 2014. "Narrative Cartography: From Mapping Stories to the Narrative of Maps and Mapping." The Cartographic Journal 51 (2): 101-106. https://doi.org/10.1179/00087 04114Z.000000000130.

Chatman, Seymour Benjamin. 1978. Story and Discourse: Narrative Structure in Fiction and Film. Ithaca, NY: Cornell University Press.

Collins, Patricia Hill. 2015. "Intersectionality's Definitional Dilemmas." Annual Review of Sociology 41 (1): 1-20. https://doi.org/10.1146/ annurev-soc-073014-112142.

Crampton, Jeremy W. 2009. "Cartography: Maps 2.0.” Progress in Human Geography 33 (1): 91-100. https:// doi.org/10.1177/0309132508094074.

2011. Mapping: A Critical Introduction to Cartography and GIS. Oxford: John Wiley \& Sons.

Crenshaw, Kimberle. 1991. "Mapping the Margins: Intersectionality, Identity Politics, and Violence Against Women of Color." Stanford Law Review 43(6): 1241-1299. https://doi.org/10.2307/1229039.

Cresswell, Tim. 2013. Geographic Thought: A Critical Introduction. Oxford: John Wiley \& Sons.

Diener, Alexander C., and Joshua Hagen. 2012. Borders: A Very Short Introduction. New York: Oxford University Press.

D'Ignazio, Catherine, and Lauren F. Klein. 2016. "Feminist Data Visualization." IEEE VIS Conference, Baltimore, October, 23-28.

Dorling, Daniel. 1993. "Map Design for Census Mapping." The Cartographic Journal 30 (2): 167-183. https://doi.org/10.1179/000870493787860175.
Elden, Stuart. 2013. The Birth of Territory. Chicago: University of Chicago Press.

England, Kim V. L. 1994. "Getting Personal: Reflexivity, Positionality, and Feminist Research." The Professional Geographer 46 (1): 80-89. https://doi. org/10.1111/j.0033-0124.1994.00080.x.

Esri. 2012. "Using Web Maps to Tell Your Story." ArcNeww. Accessed January 5, 2018. http://www.esri. com/news/arcnews/summer12articles/using-webmaps-to-tell-your-story.html.

Griffin, Amy L., and Julia Mcquoid. 2012. "At the Intersection of Maps and Emotion: The Challenge of Spatially Representing Experience." Kartographische Nacbricbten 62 (6): 291-299.

Giudice, Cristina, and Chiara Giubilaro. 2015. "ReImagining the Border: Border Art as a Space of Critical Imagination and Creative Resistance." Geopolitics 20 (1): 79-94. https://doi.org/10.1080/1465 0045.2014.896791.

Harding, Sandra. 1986. The Science Question in Feminism. Ithaca, NY: Cornell University Press.

Haraway, Donna. 1988. "Situated Knowledges: The Science Question in Feminism and the Privilege of Partial Perspective." Feminist Studies 14 (3): 575-599. https://doi.org/10.2307/3178066.

Harley, J. Brian. 1989. "Deconstructing the Map.” Cartographica: The International Journal for Geographic Information and Geovisualization 26 (2): 1-20. https:// doi.org/10.3138/E635-7827-1757-9T53.

Huffman, Daniel P. 2010. "Home." somethingaboutmaps. Accessed September 11, 2019. https:// somethingaboutmaps.com/Home.

Human Rights Watch. 2016. "Syria: Events of 2016.” Accessed January 4, 2018. https://www.hrw.org/ world-report/2017/country-chapters/syria.

Jones, Reece. 2012. Border Walls: Security and the War on Terror in the United States, India and Israel. London: Zed Books Ltd. 
Karklis, Laris, Ann Gerhart, Joe Fox, Armand Emamdjomeh, and Kevin Schaul. 2018. "Borderline: Navigating the Invisible Boundary and Physical Barriers that Define the U.S.-Mexico Border." The Washington Post. Accessed November 2, 2018. https:// www.washingtonpost.com/graphics/2018/national/ us-mexico-border-flyover/?utm_term=.2c0f37eae52e.

Kelly, Meghan. 2015a. "Mapping Syrian Refugee Border Crossings: A Critical, Feminist Analysis.” Accessed January 4, 2018. http://mappingborders.github.io.

. 2015b. "Mapping Syrian Refugee Border Crossings: A Critical, Feminist Perspective.” Master's thesis, University of Kansas.

—. 2016. "Collectively Mapping Borders." Cartographic Perspectives 84: 31-38. https://doi. org/10.14714/CP84.1363.

Knowles, Anne Kelly, Tim Cole, and Alberto Giordano. 2014. Geographies of the Holocaust. Bloomington and Indianapolis: Indiana University Press.

Kent, Alexander J., and Peter Vujakovic. 2009. "Stylistic Diversity in European State 1: 50000 Topographic Maps.” The Cartographic Journal 46 (3): 179-213. https://doi.org/10.1179/00087040 9X12488753453453.

Küchler, A. W. 1988. "Boundaries, Transitions and Continua." In Vegetation Mapping, edited by Küchler, A. W., and I. S. Zonneveld, 105-110. Dordrecht: Springer. https://doi. org/10.1007/978-94-009-3083-4_11.

Kwan, Mei-Po. 2002a. "Feminist Visualization: Re-Envisioning GIS as a Method in Feminist Geographic Research." Annals of the Association of American Geographers 92 (4): 645-661. https://doi. org/10.1111/1467-8306.00309.

2002b. "Introduction: Feminist Geography and GIS." Gender, Place, and Culture: A Journal of Feminist Geography 9 (3): 261-262. https://doi.org/10.1080/096 6369022000003860 .
2008. "From Oral Histories to Visual

Narratives: Re-Presenting the Post-September 11 Experiences of the Muslim Women in the USA." Social \& Cultural Geography 9 (6): 653-669. https://doi. org/10.1080/14649360802292462.

Ladin, Joy. 2014. "I Am Not Not Me: Unmaking and Remaking Language of the Self." Lambda Literary. Accessed January 5, 2018. http:// www.lambdaliterary.org/features/12/28/ unmaking-and-remaking-the-language-of-the-self.

Longhurst, Robyn. 1997. “(Dis)Embodied Geographies.” Progress in Human Geography 21(4): 486-501. https:// doi.org/10.1191/030913297668704177.

Lynch, Kevin. 1960. The Image of the City. Cambridge, MA: MIT Press.

MacEachren, Alan M. 1992. "Visualizing Uncertain Information.” Cartographic Perspectives 13: 10-19. https://doi.org/10.14714/CP13.1000.

Macfarlane, Robert. 2007. The Wild Places. New York: Penguin Books.

McClean, Kate. 2017. "Summer Streets Smellmapping Astor Place NYC.” Sensory Maps. Accessed January 10, 2018. http://sensorymaps.com/portfolio/ summer-streets-smellmapping-astor-place-nyc.

McColm, Lindsay K. 2012. "A Cartographic Analysis of Ecological Boundary Symbology.” Master's thesis, Lakehead University.

McLafferty, Sara L. 2002. "Mapping Women's Worlds: Knowledge, Power and the Bounds of GIS." Gender, Place and Culture: A Journal of Feminist Geography. 9 (3): 263-269. https://doi.org/10.1080/096636902200000 3879 .

Mohanty, Chandra Talpade. 1988. "Under Western Eyes: Feminist Scholarship and Colonial Discourses." Feminist Review 30: 61-88. https://doi. org/10.2307/1395054.

_ 2003. "'Under Western Eyes' Revisited: Feminist Solidarity through Anticapitalist Struggles." Signs: Journal of Women in Culture and Society 28 (2): 499-535. https://doi.org/10.1086/342914. 
Moore, Anna W., and Nicholas A. Perdue. 2014. "Imagining a Critical Geopolitical Cartography." Geography Compass 8 (12): 892-901. https://doi. org/10.1111/gec3.12187.

Näre, Lena. 2014. "Moral Encounters: Drawing Boundaries of Class, Sexuality and Migrancy in Paid Domestic Work." Ethnic and Racial Studies 37 (2): 363-380. https://doi.org/10.1080/01419870.2012.72 9669.

New York Times. 2014. "Amid Airstrikes Against ISIS, Refugees Flee Syria.” Accessed January 4, 2018. https://www.nytimes.com/interactive/2014/06/12/ world/middleeast/the-iraq-isis-conflict-in-mapsphotos-and-video.html.

Newman, David. 2006. "The Lines That Continue to Separate Us: Borders in Our 'Borderless' World.” Progress in Human Geography 30 (2): 143-161. https:// doi.org/10.1191/0309132506ph599xx.

Nold, Christian. 2009. "Emotional Cartography: Technologies of Self.” Accessed January 5, 2018. http://emotionalcartography.net.

Novaes, André Reyes. 2015. “Map Art and Popular Geopolitics: Mapping Borders between Colombia and Venezuela." Geopolitics 20 (1): 121-141. https://doi.org/ 10.1080/14650045.2014.896793.

OCHA. 2018. "About OCHA Syria.” OCHA: United Nations Office for the Coordination of Humanitarian Affairs. Accessed January 14, 2019. https://www. unocha.org/syrian-arab-republic/about-ocha-syria.

Pearce, Margaret Wickens. 2008. "Framing the Days: Place and Narrative in Cartography."

Cartography and Geographic Information Science 35 (1): 17-32. https://doi.org/10.1559/152304008783475661.

Pearce, Margaret Wickens, and Michael James Hermann. 2010. “Mapping Champlain's Travels: Restorative Techniques for Historical Cartography." Cartographica 45 (1): 32-46. https://doi.org/10.3138/carto.45.1.32.

Popescu, Gabriel. 2011. Bordering and Ordering the Twenty-First Century: Understanding Borders. Lanham, MD: Rowman \& Littlefield Publishers.
Rajaram, Prem Kumar, and Carl Grundy-Warr. 2007. Borderscapes: Hidden Geographies and Politics at Territory's Edge. Minneapolis: University of Minnesota Press.

Reutzel, D. Ray. 1985. "Story Maps Improve

Comprehension." The Reading Teacher 38 (4): 400-404.

Rich, Adrienne. 2003. "Notes towards a Politics of Location.” In Feminist Postcolonial Theory: A Reader, edited by Reina Lewis and Sarah Mills, 29-42. New York and Abingdon: Routledge.

Rose, Gillian. 1993. Feminism E Geography: The Limits of Geographical Knowledge. Minneapolis: University of Minnesota Press.

Rossum, Sonja, and Stephen Lavin. 2000. "Where Are the Great Plains? A Cartographic Analysis.” Professional Geographer 52 (3): 543-552. https://doi. org/10.1111/0033-0124.00245.

Rumford, Chris. 2006. “Theorizing Borders.” European Journal of Social Theory 9 (2): 155-169. https://doi. org $/ 10.1177 / 1368431006063330$.

Salamon, Gayle. 2006. “The Place Where Life Hides Away': Merleau-Ponty, Fanon, and the Location of Bodily Being." differences 17 (2): 96-112. https://doi. org/10.1215/10407391-2006-004.

Salopek, Paul. 2015. "Fleeing Terror, Finding Refuge: Millions of Syrians Escape an Apocalyptic Civil War, Creating a Historic Crisis.” National Geographic. Accessed November 14, 2019. https:// www.nationalgeographic.com/magazine/2015/03/ syrian-civil-war-refugees-fleeing-terror.

Samantrai, Ranu. 2004. “Cosmopolitan Cartographies: Art in a Divided World." Meridians: Feminism, Race, Transnationalism 4 (2): 168-198. https://doi. org/10.1353/mer.2004.0034.

Slocum, Terry A., Robert Bach McMaster, Fritz C. Kessler, and Hugh H. Howard. 2009. Thematic Cartography and Geovisualization, Third Edition. Upper Saddle River, NJ: Prentice Hall. 
Sprunk, Dana. 2010. “Geography of Body.” In Encyclopedia of Geography, edited by Barney Warf, 288-291. Thousand Oaks, CA: SAGE Publications, Inc. https://doi.org/10.4135/9781412939591.n113.

Sullivan, Kevin. 2013. "Refuge: 18 Stories from the Syrian Exodus." The Washington Post. Accessed January 4, 2018. http://www.washingtonpost.com/sf/ syrian-refugees/story/refuge.

van Swaaij, Louise, and Jean Klare. 2000. The Atlas of Experience, translated by David Winner. New York: Bloomsbury.

UNHCR. 2014. "Needs Soar as Number of Syrian Refugees Tops 3 Million.” UNHCR: The UN Refugee Agency. Accessed June 20, 2017. http://www.unhcr. org/en-us/news/latest/2014/8/53ff76c99/needs-soarnumber-syrian-refugees-tops-3-million.html.

. 2017. "Flash Update: Syrian Refuge and IDP Returns (30 June 2017)." Reliefweb. Accessed January 4, 2018. https://reliefweb.int/report/syrian-arabrepublic/flash-update-syrian-refugee-idp-returns-30june-2017.
2018. "Syria Regional Refugee Response." UNHCR Syria Regional Refugee Response. Accessed January 4, 2018. http://data.unhcr.org/syrianrefugees/ regional.php.

Valentine, Gill. 1999. "A Corporeal Geography of Consumption." Environment and Planning D: Society and Space 17 (3): 329-351. https://doi.org/10.1068/ d170329.

Wood, Denis. 1987. "Pleasure in the Idea/The Atlas as Narrative Form.” Cartographica 24 (1): 24-46. https:// doi.org/10.3138/3163-659q-j502-w858.

Wood, Denis, and John Fels. 1992. The Power of Maps. New York: Guilford Press.

Yuval-Davis, Nira, and Marcel Stoetzler. 2002. "Imagined Boundaries and Borders A Gendered Gaze." European Journal of Women's Studies 9 (3): 329-344. https://doi.org/10.1177/135050680200900 3378. 